rev.relac.int.estrateg.segur.5(2):73-108,2010

\title{
ESTADOS FALLIDOS: ¿AMENAZA GLOBAL O REGIONAL?
}

\author{
Antonio M. Camargo \\ Freddy A. Guáqueta \\ Javier F. Ramírez
}

\section{RESUMEN}

Los Estados fallidos han sido entendidos como una amenaza global en virtud de los grupos terroristas que emergen y se consolidan en su interior, desde donde se supone planean acciones internacionales. El presente documento, sin embargo, deslinda el impacto de la falla estatal al ámbito regional, como quiera que son los países vecinos de un Estado fallido los que, a través de sus fronteras, ven modificadas sus dinámicas internas debido a dos factores principales: los tráficos ilegales causados por la ausencia de controles efectivos por parte del Estado, y las grandes cantidades de refugiados que cruzan las fronteras más inmediatas de su fallido lugar de origen y se asientan en los países más cercanos. Por tanto, se desmiente en buena medida la idea según la cual la repercusión del fracaso de algunos Estados trae consigo la invariable consecuencia de un ataque terrorista de dimensiones globales, más bien se trata de reconocer que son sus vecinos regionales los que resultan impactados por sus anomalías.

Integrantes del Semillero de Estudios Políticos en la Posguerra Fría SEPEP- de la Universidad del Rosario. Línea de investigación «Estados fallidos»antoniomcamargod@hotmail.com. 
Palabras clave: Estados fallidos, terrorismo, refugiados, áreas sin gobierno, crimen organizado internacional, amenaza global, amenaza regional.

\begin{abstract}
Failed States have been understood as a global threat by virtue of the terrorist groups that emerge and consolidate in their interior, where they are supposed to plan international actions. This document, however, delimits the impact of the state failure to regional confines, inasmuch as the neighboring countries of a failed State are the ones that, through their borders, see their internal dynamics modified due to two main factors: the illegal traffic caused by the absence of effective controls on the part of the State, and the large quantities of refugees that cross the borders closest to their failed place of origin and settle in nearby countries. Therefore, it is refuted in good measure the idea that repercussions of the failure of some States, bring the invariable consequence of a terrorist attack of global dimensions; instead, it is a matter of recognizing that their regional neighbors are the ones that are impacted by the anomalies of the Failed States.
\end{abstract}

Key Words: Failed states, terrorism, refugees, ungoverned areas, international organized crime, global threat, regional threat.

\title{
INTRODUCCIÓN
}

Pese a que el interés académico frente a la falla de los Estados no es una novedad, sí lo es la caracterización y connotación política que gobiernos y agencias han puesto en el fenómeno a partir de los hechos del 11 de septiembre de 2001. Desde entonces, gobiernos, instituciones y centros de investigación han invertido buena parte de sus recursos para la comprensión y evaluación de los procesos inherentes al fracaso o debilitamiento estatal.

La discusión sobre los Estados fallidos se halla dividida fundamentalmente en dos corrientes: la conservadora y la crítica. La primera de ellas tiene a Robert Rotberg y a Francis Fukuyama entre sus principales exponentes y, aún más, esta doctrina se ha relacionado de manera recurrente al gobierno de George W. Bush. Ella plantea que la falla estatal es consecuencia de la agencia humana, es decir, de la incapacidad técnica, gerencial o corrupción por parte de las clases dirigentes a la hora de gobernar el país, lo cual desemboca en la privación de bienes políticos a la población y su posterior desenlace en hechos de violencia e ilegalidad.

Además, la mirada conservadora parte del Estado como una institución universal y universalizable, y en esta medida le corresponde a los Estados más estables intervenir en los procesos de falla de los diferentes países fracasados o en vías de serlo. Precisamente, la intervención se plantea bajo el argumento de que los Estados fallidos son una amenaza a la esta- 
bilidad del globo en su totalidad, punto en el cual se encuentran las mayores divergencias con la posición crítica.

Por su parte, los críticos de la categoría de Estado fallido -Jeffrey Herbst, Susan Woodward, Christopher Clapham, Morten Boas, Kathleen Jennings, etc.- argumentan que el discurso del fracaso estatal entraña consigo el intervencionismo de las potencias, especialmente de Estados Unidos, en países que se determinan como fallidos, además, siendo esta categoría asumida desde la óptica del deber ser del Estado, hijo de los procesos de la modernidad occidental. Esto desconoce, desde la mirada crítica, diferentes formas de asumir el poder en terrenos no occidentales, las causas de falla relacionadas con las responsabilidades de los países potencia en la misma y finalmente deriva en la imposición de medidas permeadas por el interés económico y político de los países interventores, que algunos se atreverían a denominar neocolonialistas.

Patricia Moncada Roa brinda una aproximación a la categoría de Estados fracasados o fallidos, entendidos como aquellos que «no controlan su territorio, han perdido el monopolio de la fuerza o rivalizan por éste con grupos armados que operan dentro de sus fronteras, han perdido legitimidad frente a amplios sectores de la población, han perdido la capacidad -por completopara proporcionar servicios públicos o para proporcionarlos en niveles razonables, han perdido la capacidad para desempeñarse en la esfera internacional como los demás Estados soberanos, tienen gobiernos muy corruptos, etcétera» ${ }^{1}$.

Así pues, la discusión alrededor de los Estados fallidos resulta de gran impacto para temas como el terrorismo, intervencionismo, desarrollo y subdesarrollo, entre otros de diferente recurrencia en el panorama de la Ciencia Política y las Relaciones Internacionales. Este artículo pretende delimitar la discusión sobre la amenaza de los Estados fallidos al ámbito regional. Aunque los Estados fallidos se han entendido como una amenaza global en tanto se parte del supuesto que en ellos se localiza el origen y desarrollo de grupos terroristas, es posible replantear sus repercusiones en términos regionales a la luz de problemas fronterizos como los tráficos ilegales y los refugiados.

El impacto del fracaso estatal no se reduce al interior del mismo país en forma exclusiva. Lo que se debe preguntar es si este impacto tiene realmente un carácter mundial, si los sucesos propios de países en grave condición en África, por tomar uno solo de los ejemplos, implica serios cambios en el panorama de todos los países del mundo, o si más bien su impacto internacional -que es innegable que lo tiene-compromete a sus países aledaños, al vecindario del cual hace parte, a la región específica en la cual se localiza el Estado fallido. Así pues, el presente artículo, en su primera parte, se concentra en dilucidar el vínculo entre terrorismo y Estados Fallidos, con el

1 Patricia Moncada Roa, Los Estados fallidos o fracasados: un debate inconcluso y sospechoso, Siglo del Hombre Editores, 2007, p. 42-43. 
ánimo de poner a prueba la tesis dominante sobre los Estados Fallidos como criaderos del terrorismo. En la segunda parte se analizarán ciertas amenazas fronterizas específicamente en zonas de prominente falla estatal, para ir perfilando el impacto regional de los Estados fallidos y, así, en la tercera parte profundizar en el tema de los refugiados como problemática regional concreta.

\section{ESTADOS FALLIDOS Y TERRORISMO}

Desde diferentes escenarios se ha declarado que los Estados fallidos son tierra fértil para el surgimiento y expansión de grupos terroristas. En efecto, aunque después del 11-S la idea se diseminó con rapidez, antes de los atentados ya existían varios trabajos que insinuaban este vínculo (Dorff, 1996; Reno, 1998; Friman y Andreas, 1999; Jordan, 1999)². Tanto políticos como estudiosos del tema han desarrollado una terminología específica para referirse a esta situación, se califica a los Estados fallidos como «refugios seguros», «tierra fértil», «santuarios» o «criaderos» del terrorismo, y se colige, por tanto, que representan una amenaza global. Es significativo que una aproximación a los Estados fallidos como amenaza esté presente en la Estrategia de Seguridad Nacional de Estados Unidos, en la Estrategia de Seguridad Nacional del Reino Unido y en la Estrategia Europea de Seguridad, con un enfoque relativamente unificado no sólo en cuanto se reconoce la amenaza, sino en tanto la intervención se considera necesaria para resguardar la seguridad de occidente.

EI US National Intelligence Council afirma que «los conflictos internos pueden producir la falla del Estado, o un Estado fallido, con amplios territorios y poblaciones al margen del control efectivo del gobierno. En esos casos, estos territorios pueden convertirse en santuarios para terroristas transnacionales como Al-Qaeda» ${ }^{3}$. Los Estados fallidos, en este momento, son observados como una amenaza potencial donde los terroristas, al tomar ventaja de un Estado incapaz de controlar su territorio, pueden planear y organizar acciones contra Estados Unidos. Un paso más adelante llega la apreciación del 9/11 Commission Report al sugerir lo siguiente:

«Estados Unidos ha tenido que encontrar maneras de ampliar su alcance, forzando los límites de su influencia (...). Toda decisión política que tomemos debe ser vista a través de estos lentes. Si, por ejemplo, Irak se convierte en un Estado fallido, tiene que llegar al primer puesto en la lista de lugares que son caldo de cultivo para ataques contra los americanos en casa. Similarmente, si no ponemos suficiente atención a Afganistán, el gobierno de los talibanes, señores de la guerra o narcotraficantes puede resurgir, y su territorio una vez más podría ofrecer refugio a Al-Qaeda, o a sus sucesores» ${ }^{4}$

2 Robert Dorff. Failed States After 9/11: What Did We Know and What Have We Learned? International Studies Perspectives (2005) 6, 22.

3 National Intelligence Council, Mapping the global Future P. 98.

4 The 9/11 Comission Report. p. 367. 
La Estrategia de Seguridad Nacional de los Estados Unidos también alude al nexo entre Estados fallidos y terrorismo:

«Terroristas transnacionales son reclutados de las personas que no tienen voz en su propio gobierno y no ven ninguna manera legítima para promover el cambio en su propio país. Sin una participación en el orden existente, son vulnerables a la manipulación por parte de quienes abogan por una visión perversa sobre la base de la violencia y la destrucción» ${ }^{5}$.

Las anteriores referencias ilustran algunas instancias donde aparecen alusiones a los Estados fallidos desde una perspectiva de amenaza, los Estados que no logran control del territorio y la población ni establecen de forma eficaz el imperio de la ley, se supone tienen predisposición para albergar grupos terroristas. La intervención, en esta línea de pensamiento, aparece como un asunto estratégico en el marco de la lucha contra el terror, al permitir anticiparse al surgimiento mismo de los grupos terroristas por medio de la eliminación previa de su «hábitat», es decir, al establecer una democracia efectiva en un otrora Estado fallido ${ }^{6}$.

Sin duda Estados Unidos ha sido el abanderado en la lucha contra el terror, desde el 9/11 el terrorismo se convierte en un tópico omnipresente, acaso hipertrofiado, por los políticos, los medios de comunicación y un sin número de académicos. Sin embargo, en otras latitudes también se articula el vínculo entre Estados fallidos y terrorismo a través de un discurso estructurado bajo las premisas generales estadounidenses. La Estrategia de Seguridad Nacional del Reino Unido le dedica un acápite completo al tema de Estados fallidos y frágiles donde asevera que, «actualmente, la mayoría de las grandes amenazas y riesgos emanan de Estados fallidos o frágiles», Estados que por demás no tienen la capacidad para hacer frente al terrorismo ${ }^{7}$.

Si bien de los cuatro terroristas que perpetraron el atentado del 2005 en Londres tres eran británicos, (Mohammed Sidique Khan, Shehzad Tanweer, Hasib Hussain, y la jamaiquina Germaine Lindsay vivía en West Yorkshire desde los 5 meses de edad), las autoridades británicas se empeñaron en afirmar que la amenaza terrorista provenía de Estados fallidos ${ }^{8}$.

5 The National Security Estrategy of the United States of America. P. 10.

6 El autor Brennan Kraxberger elabora un interesante análisis sobre democracia y Estados fallidos en su artículo Failed states: temporary obstacles to democratic difusión or Fundamentals holes in the World political map? Cabe resaltar que Kraxberger considera como requisitos de la democratización ciertos niveles mínimos de estatalidad, por lo menos en cuanto a cohesión social (armonía intergrupal) y consenso en torno a la organización territorial del Estado, en aras de evitar movimientos separatistas. Las investigaciones de Przeworski y Lipset sobre la relación entre desarrollo económico y democracia sugieren que existe algún vínculo entre nivel de ingresos y establecimiento de la democracia, por lo cual se pone también en duda que la democracia pueda aflorar fácilmente en Estados colapsados (o fallidos en estado crítico) y servir como remedio inmediato a sus dolencias.

7 The National Security Strategy of the United Kingdom. P. 14.

8 Dan Bulley, 'Foreign' Terror? London Bombings, Resistance and the Failing State, P. 381. 
Las investigaciones incluso lograron develar que el financiamiento de las acciones terroristas se realizó de forma local por medio de un préstamo bancario, así como el «Know-How» en explosivos fue desarrollado internamente. A pesar de las pruebas, como señala Dan Bulley, se efectuó una exteriorización de los ataques bajo el discurso de los Estados fallidos entendidos como fuente de las ideologías que alimentan el terrorismo, y base de las escuelas y campos de adoctrinamiento ${ }^{9}$.

Las posiciones que tradicionalmente asocian el terrorismo con los Estados fallidos no se basan, hasta donde se ha mostrado, en estudios concretos cimentados en un análisis riguroso de los Estados fallidos como fenómeno particular. Cuando se afirma que «el colapso del Estado puede asociarse con amenazas evidentes como la delincuencia organizada o el terrorismo (...) $\rangle^{10}$, se está conjeturando acerca de los posibles efectos de un colapso estatal. No obstante, aparte de unos casos paradigmáticos como el de Afganistán e Iraq, no es palmario en terreno que los Estados fallidos actúen como santuarios del terrorismo. Por supuesto esta tesis ha hecho carrera con gran facilidad porque a simple vista parece obvia, no debería levantar sospecha el afirmar que un Estado fallido puede albergar terrorismo, la frase se ajusta sin equívocos al sentido común. Una inspección más detallada revela que no está claro el vínculo. Por ejemplo, el hecho de que AlQaeda se hubiese desplegado en Afganistán, y que Afganistán fuese catalogado como Estado fallido, lo único que confirma es que, en efecto, hay un grupo terrorista en un Estado fallido, mas no explica si la falla estatal es el aspecto puntual que permite el surgimiento del grupo terrorista o, en cambio, es otra cualidad del Estado la causante. Lo que se sugiere en esta instancia es la necesidad de develar si existe una relación causal entre Estado fallido y terrorismo, si hay pruebas de algún tipo que corroboren la postura dominante o por el contrario que la desmientan.

En el ámbito académico los aportes de Robert Rotberg tal vez han sido los más influyentes en la discusión sobre Estados fallidos, en especial «Failed States in a World of Terror»y «The New Nature of Nation-State Failure». La asociación entre Estados fallidos y terrorismo no es trabajada por este pensador de forma específica, aparece en medio de análisis generales sobre los Estados fallidos y sus características sociales, políticas y económicas ${ }^{11}$; en este sentido es comprensible que las apreciaciones de Rotberg sean esencialmente las mismas que se han mostrado anteriormente en las estrategias de seguridad. Por su parte, los análisis anteriores al 9/11 (Drug Politics: Dirty Money and Democracies Jordan 1999; Democratization and Failed States: The Challenge of Ungovernability Dorff 1996; The Illicit Global Economy and State Power Friman y Andreas, 1999) no cuentan con un perfil claro de lo que constituye un Estado fallido puesto que la discusión apenas estaba en ciernes. Quizá el estudio más reciente que sustenta el vínculo entre Estados fallidos y terrorismo de forma explícita lo constituye el artículo de Peter Tikuisis «On the relationship between weak states and terrorism» publicado en el 2009. Curiosamente, aunque

\footnotetext{
9 Ibid., P. 382.

10 Una Europa Segura en Un Mundo Mejor. Estrategia de Seguridad Europea, P. 4.

11 Robert Rotberg, Failed States in a World of Terror, P. 3.
} 
el artículo se concentra en controvertir los trabajos de Aidan Hehir y Edward Newman (The Myth of the Failed States and the War on Terror: A Challenge to the Conventional Wisdom y Weak State, State Failure and Terrorism, respectivamente), Tikuisis sustenta la relación entre Estados fallidos y terrorismo a partir de la metodología de aquellos quienes justamente se habían encargado de refutarla.

Poner a prueba la posición dominante obliga que fueran probadas con datos empíricos las siguientes asunciones. 1) Si existiera una relación causal Estados fallidos-terrorismo se esperaría que en los Estados que encabezan el «Failed State Index» hubiese amplia presencia de grupos terroristas, 2) además, si los Estados fallidos son criaderos del terrorismo, en consecuencia los Estados fuertes, o exitosos, no tendrían presencia terrorista relevante. El problema inicial de estudio estriba en la ambigüedad de una de las variables, a saber, el término de Estado fallido ${ }^{12}$ que en algunos autores es utilizado como sinónimo de Estado débil (Newman y Tikuisis) aunque otros desaprueban claramente su homologación con conceptos como «Quasi-estado», «Estado colapsado», «Estado débil» o «Estado Canalla» ${ }^{13}$. El debate sobre el concepto de Estado fallido se puede retrotraer hasta poner en duda la existencia misma de los Estados fallidos. Algunos aducen que el concepto es puro discurso político basado en la seguridad e intereses de occidente ${ }^{14}$, sin embargo aquí se parte de los Estados fallidos como una realidad relativamente tangible aunque difícil de aprehender.

Un segundo problema deriva de la utilización del «Failed State Index» ${ }^{15}$, pues este reciente ranking a su vez ha recibido copiosas $\mathrm{críticas}^{16}$, algunos políticos y académicos han recriminado la ubicación de estados como Colombia, Perú o República Dominicana. De igual forma, las inconsistencias entre los informes de ACNUR y los indicadores de refugiados manejados por FundFor Peace son evidentes, por lo cual es posible pensar en algún error metodológico en este punto. A pesar de todo se considera el índice como un insumo válido que de hecho ha sido utilizado por Newman, Hehir y Tikuisis para analizar Estados fallidos y terrorismo, si bien cabe mencionar que Newman utiliza fuentes alternativas como el Banco Mundial.

El presente análisis contrasta la existencia de grupos terroristas con la ubicación de los distintos países en el Failed State Index. La discusión con respecto a este trabajo, que en líneas generales

\footnotetext{
12 Aidan Hehir, The Myth of the Failed States and the War on Terror: A Challenge to the Conventional Wisdom, P. 312-314. y Edward Newman, Weak State, State Failure and Terrorism, P. 464.

13 Pinar Bilgin y Adam David Morton, Historicing representations of «failed states»: beyond the cold-war annexation of the social sciences?, P. 55-56.

${ }_{14}$ Morten Boas y Kathleen Jennings, Failed States and State Failure: Threats or Opportuniies, P. 475.

15 Lista que anualmente clasifica a los países desde doce diferentes problemáticas (presiones demográficas, refugiados y desplazados, agravios colectivos, fugas humanas, desarrollo desigual, economía, deslegitimación, del Estado, servicios públicos, derechos humanos, aparatos de seguridad, élites divididas e intervención externa) y que para el año 2009 determinó 38 países como los Estados más críticos o fallidos.

16 Luis Alberto Moreno et. al. A Failed Index?, P. 4.
} 
asume la metodología utilizada por Aidan Hehir, radica en las críticas expuestas por Newman y Tikuisis al uso de la variable número de grupos terroristas por país, incluyendo la presencia de cualquier grupo terrorista existente de acuerdo con las investigaciones del MIPT (National Memorial Institute for the Prevention of Terrorism). Para Newman, una lista combinada de grupos terroristas cae en el error de mezclar organizaciones que varían en tamaño, objetivos y nivel de amenaza $^{17}$, para él es más adecuado utilizar una lista que incluya sólo los grupos más letales en cuanto al número de fatalidades que son capaces de producir. Tikuisis, aunque asume una lista limitada al igual que Newman, reúne todos los grupos terroristas que causan fatalidades independientemente de su tamaño. La lista de Tikuisis se diferencia de la de Newman en que asume cualquier grupo que causa fatalidades en lugar de los grupos que causan mayor número de fatalidades. Por supuesto, en un análisis cuantitativo como el que elaboran esta pequeña diferencia implica llegar a conclusiones distintas. Mientras Newman encuentra que los Estados fallidos albergan grupos terroristas letales, sin llegar a ser la causa del terrorismo, Tikuisis afirma que en efecto existe una relación causal entre Estados fallidos y terrorismo.

Seleccionar los grupos terroristas más letales para examinar la relación entre Estados fallidos y terrorismo es una forma de inclinar la balanza en contra de los Estados que tienen menor capacidad para contrarrestarlo. Aunque la conclusión de Newman puede llegar a ser plausible, en tanto los grupos más letales se encuentran primordialmente en Estados fallidos, en su análisis se desconocen grupos emergentes o grupos que a pesar de su existencia han sido controlados por las fuerzas nacionales de seguridad. La potencialidad destructiva de estos grupos queda fuera del análisis de Newman al optar por aquellos que causan mayor número de fatalidades. El terrorismo queda reducido, desde esta perspectiva, al número de muertes, sin tener en cuenta las operaciones de organización, financiación, planeación y ejecución que existen en el accionar de estos grupos. La visión del terrorismo como fatalidades reduce un fenómeno complejo a su expresión más tangible, más evidente, o acaso más sensacionalista, sin observar todas las acciones previas que permiten atentados de gran impacto.

La aproximación de Tikuisis también es problemática pues al seleccionar todos los grupos que causan fatalidades se niega la relevancia, por ejemplo, de aquellos terroristas que vieron frustrado su intento. El nigeriano Umar Farouk Abdulmutallab, que recientemente falló en su tentativa de hacer explotar un avión en Detroit, no tiene ninguna relevancia para Tikuisis; de haber estallado seguro haría parte de su análisis. Entonces ¿Cuál es la diferencia de fondo entre un atentado fatal y uno frustrado? La diferencia, en primera instancia, puede estar en la capacidad del grupo terrorista, en segunda instancia, en la eficacia de las fuerzas de seguridad de un país, no obstante al margen de lo anterior lo que es claro que las fatalidades no son un indicador de la existencia del terrorismo, sino más bien de su capacidad.

Como el presente estudio se concentra en la existencia de grupos terroristas más que en su capacidad, con el propósito de analizar la relación terrorismo-Estados fallidos, se ha optado por

17 Edward Newman, Weak State, State Failure, and Terrorism, P. 473. 
una lista amplia donde se incluyen todos los grupos registrados en cada país. Con esta lista se asume el terrorismo como un fenómeno complejo con variedad de grupos que son relevantes por sus intensiones terroristas más que por su capacidad de llevarlas a cabo. Además, la lista que se utiliza tiene la ventaja de ser más neutral políticamente al no discriminar grupos por alguna razón particular y con ello caer en distorsiones (como ya se mencionó, abordar el terrorismo desde las fatalidades favorece a aquellos países que tienen mayor capacidad para contenerlo).

De los 38 estados que se catalogan como en nivel de alerta en el Failed State Index, 9 no cuentan con ningún grupo terrorista, y en promedio contarían con 8 grupos cada uno, sin embargo en vista del valor extremo de Irak con 84 grupos, es más estimable el valor de la mediana, 3 grupos terroristas por país. Es muy diciente que la moda sea 0 , pues indica que un buen número de Estados fallidos no muestran presencia terrorista en contra de la tesis expuesta por las Estrategias de Seguridad (Ver cuadro 1). La gráfica ilustra que no necesariamente los Estados más fallidos tienen mayor número de grupos terroristas los casos de Líbano e Irán que se ubican en los puestos 29 y 38, con 54 y 17 grupos terroristas respectivamente, son prueba de ello. En este primer análisis se esperaría encontrar un número decreciente de grupos terroristas a medida que se alejan los países de los primeros lugares del índice, pero la forma de la gráfica no permite vislumbrar algún tipo especial de tendencia.

Tabla 1.

Failed State Index 2009 primeros 38 países Vs. Global Terrorism Database.

\begin{tabular}{|l|c|}
\hline \multicolumn{1}{|c|}{ Failed State Index $\mathbf{2 0 0 9}^{\mathbf{1 8}}$} & $\begin{array}{c}\text { Global Terrorism Database }^{\mathbf{1 9}} \\
\text { (Número de grupos terroristas por país) }\end{array}$ \\
\hline 1. Somalia & 5 \\
\hline 2. Zimbabwe & 1 \\
\hline 3. Sudan & 7 \\
\hline 4. $\quad$ Chad & 3 \\
\hline 5. República Democrática del Congo & 7 \\
\hline 6. Irak & 84 \\
\hline 7. Afganistán & 16 \\
\hline 8. República Centroafricana & 0 \\
\hline 9. Guinea & 0 \\
\hline 10. Pakistán & 32 \\
\hline 11. Costa de Marfil & 1 \\
\hline 12. Haití & 3 \\
\hline 13. Burma & 0 \\
\hline
\end{tabular}

${ }^{18}$ Ver, The Fund For Peace. Failed States Index 2009. http://www.fundforpeace.org/

${ }_{19}$ Ver, http://www.start.umd.edu/start/data/tops/ 


\begin{tabular}{|l|c|}
\hline 14. Kenya & 2 \\
\hline 15. Nigeria & 5 \\
\hline 16. Etiopia & 8 \\
\hline 17. Corea del Norte & 0 \\
\hline 18. Yemen & 6 \\
\hline 19. Bangladesh & 20 \\
\hline 20. Timor Oriental & 0 \\
\hline 21. Uganda & 5 \\
\hline 22. Sri Lanka & 4 \\
\hline 23. Niger & 1 \\
\hline 24. Burundi & 0 \\
\hline 25. Nepal & 4 \\
\hline 26. Camerún & 1 \\
\hline 27. Guinea-Bissau & 0 \\
\hline 28. Malawi & 0 \\
\hline 29. Líbano & 54 \\
\hline 30. República del congo & 1 \\
\hline 31. Uzbekistan & 3 \\
\hline 32. Sierra leona & 1 \\
\hline 33. Georgia & 3 \\
\hline 34. Liberia & 2 \\
\hline 35. Burkina faso & 0 \\
\hline 36. Eritrea & 4 \\
\hline 37. Tajikistan & 3 \\
\hline 38. Irán & 17 \\
\hline
\end{tabular}

Gráfica 1. Primeros 38 países Vs. grupos terroristas por país.

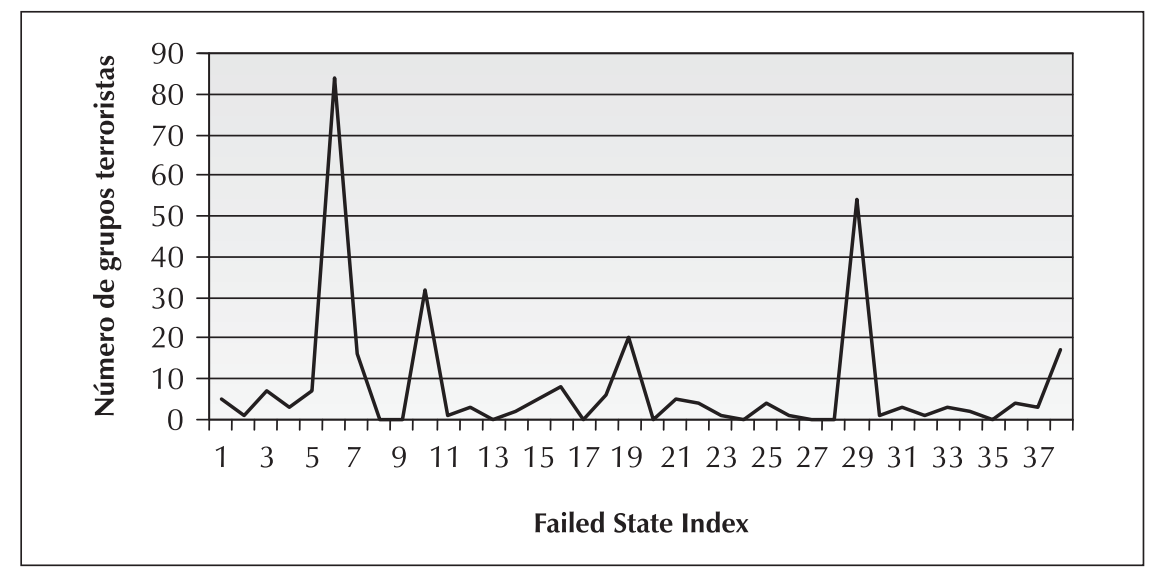


Un análisis de los Estados no fallidos, es decir, los últimos 38 del índice, todos aquellos considerados como sostenibles y otros moderados, revela que aun continúan existiendo países con amplia presencia terrorista. En este caso cada país tiene 10 grupos terroristas en promedio mientras los 38 Estados fallidos tenían 8 grupos, una diferencia de dos. Con el valor de la mediana también los Estados no fallidos superan a los Estados fallidos con 3.5 frente a 3 grupos por país. La moda para esta cohorte de países también es 0 , lo que muestra que ambos grupos se inclinan hacia la ausencia de grupos terroristas (Ver cuadro 2). En la gráfica 2 al igual que en la 1, no se puede observar una tendencia a disminuir a medida que los países se alejan de los primeros lugares del índice, de hecho los primeros países de este grupos ubicados del puesto 140 al 146 no tienen presencia terrorista relevante, mientras otros países ubicados en mejores posiciones como Estados Unidos (159) o Francia (158) tienen por mucho mayor cantidad de grupos (68 y 51 respectivamente). El análisis comparativo entre estos dos grupos, los Estados fallidos Vs los Estados no fallidos, muestra un panorama bastante homogéneo en cuanto a presencia de grupos terroristas, e incluso un poco inclinado hacia la mayor presencia en Estados no fallidos que en estados fallidos (Promedio mayor 10 Vs 8, media mayor 3.5 Vs 3, mayor valor Grecia con 86 Vs Irak con 84, total presencia grupos 395 Vs 303). De acuerdo con esto no es posible encontrar relación entre Estados fallidos y terrorismo como se suele afirmar en múltiples escenarios.

Tabla 2.

Failed State Index 200938 países más estables Vs. Global Terrorism Database.

\begin{tabular}{|ll|c|}
\hline Failed State Index 2009 & $\begin{array}{c}\text { Global Terrorism Database } \\
\mathbf{2 1} \\
\text { (Número de grupos terroristas por país) }\end{array}$ \\
\hline 140 Estonia & 2 \\
\hline 141 Hungria & 0 \\
\hline 142 Polonia & 1 \\
\hline 143 Malta & 0 \\
\hline 144 Eslovaquia & 0 \\
\hline 145 Lituania & 1 \\
\hline 146 & Oman & 06 \\
\hline 147 Grecia & 3 \\
\hline 148 Mauritania & 12 \\
\hline 149 Argentina & 34 \\
\hline 150 Italia & 14 \\
\hline 151 España & 0 \\
\hline 152 República Checa & \\
\hline
\end{tabular}

${ }^{20}$ Ver, The Fund For Peace. Failed States Index 2009. http://www.fundforpeace.org/

21 Ver, http://www.start.umd.edu/start/data/tops/ 


\begin{tabular}{|l|c|}
\hline 153 Corea del Sur & 0 \\
\hline 154 Uruguay & 4 \\
\hline 155 Chile & 8 \\
\hline 156 Eslovenia & 0 \\
\hline 157 Alemania & 18 \\
\hline 158 Francia & 51 \\
\hline 159 Estados Unidos & 68 \\
\hline 160 Singapur & 1 \\
\hline 161 Reino Unido & 23 \\
\hline 162 Bélgica & 7 \\
\hline 163 Portugal & 4 \\
\hline 164 Japón & 10 \\
\hline 165 Islandia & 0 \\
\hline 166 Canada & 6 \\
\hline 167 Luxemburgo & 0 \\
\hline 168 Austria & 3 \\
\hline 169 Holanda & 10 \\
\hline 170 Australia & 5 \\
\hline 171 Nueva Zelanda & 0 \\
\hline 172 Dinamarca & 3 \\
\hline 173 Irlanda & 6 \\
\hline 174 Suiza & 11 \\
\hline 175 Suecia & 4 \\
\hline 176 Finlandia & 0 \\
\hline 177 Noruega & 0 \\
\hline
\end{tabular}

Gráfica 2. Últimos 38 países Vs. Grupos terroristas.

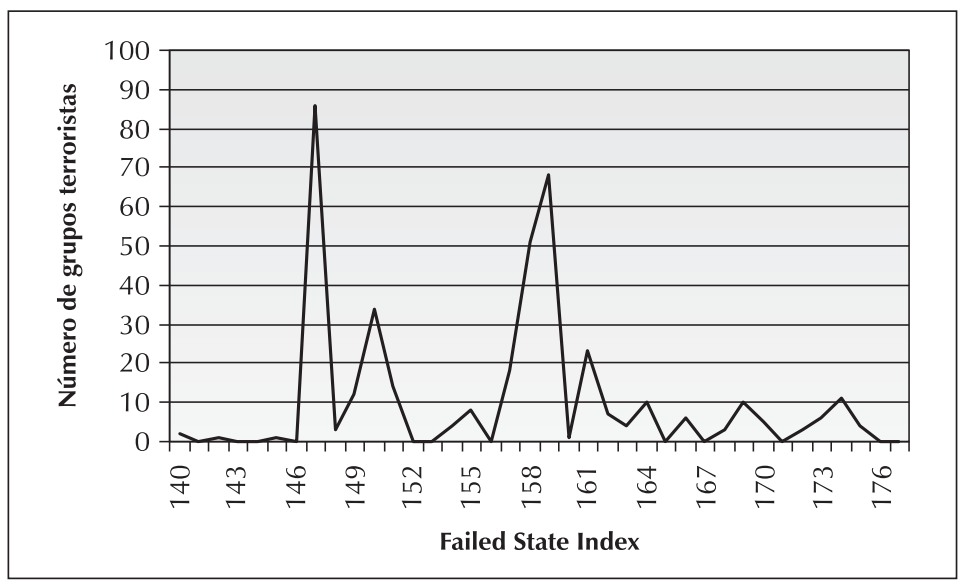


Una muestra de un subgrupo de países como los del G8 considerados potencias, evidencia una alta relación con presencia terrorista a pesar de estar bien ubicados en el Failed State Index, tal vez a excepción de Rusia (71) (Ver tabla 3 y Gráfica 3). Para esta cohorte los valores 28 y 20.5 representan el promedio y la mediana respectivamente, por lo cual es patente que la presencia terrorista en las potencias claramente más acentuada que en los otros países analizados. Como aseveran Simons y Tucker, la infraestructura desempeña un rol importante para los grupos terroristas, lo cual puede llevar a desincentivarlos a la hora de situarse en un Estado fallido y por el contrario los exhortaría a utilizar como base un Estado fuerte ${ }^{22}$.

Tabla 3.

Países del G8 Vs. Global Terrorism Database

\begin{tabular}{|c|c|}
\hline Países del G8 & $\begin{array}{c}\text { Global Terrorism Database } \\
\text { (Número de grupos terroristas por país) }\end{array}$ \\
\hline 159 Estados Unidos & 68 \\
\hline 158 Francia & 51 \\
\hline 166 Canada & 6 \\
\hline 150 Italia & 34 \\
\hline 157 Alemania & 18 \\
\hline 161 Reino Unido & 23 \\
\hline 164 Japón & 10 \\
\hline $71 \quad$ Rusia & 16 \\
\hline
\end{tabular}

Gráfica 3. Países del G8 Vs. Número de grupos terroristas.

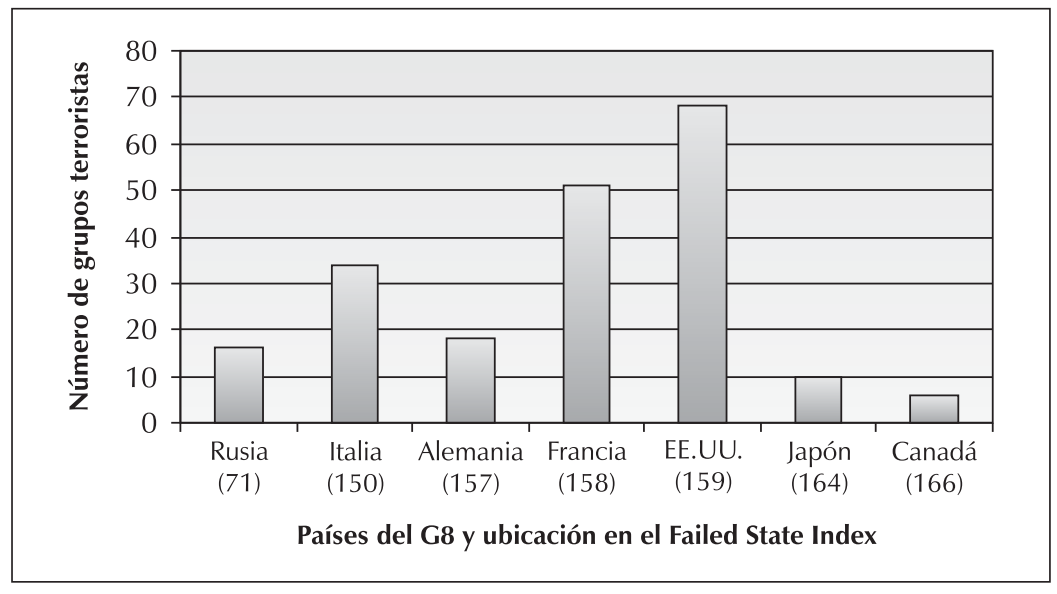

${ }^{22}$ Anna Simons y David Tucker, The misleading Problem of Failed States: a «socio-geography» of terrorism in the post 9/11 era. P. 389. 


\section{ESTADOS FALLIDOS Y AMENAZAS TRANSFRONTERIZAS}

El interés que Estados Unidos ha puesto en el fenómeno de los Estados fallidos a partir de los hechos del 11 de septiembre de 2001 muestra una nueva perspectiva que centra su atención en varias amenazas procedentes de estos Estados. Tales amenazas incluyen refugiar terroristas y otros grupos ilegales; causar o exacerbar conflictos violentos; propiciar redes criminales y economías ilícitas; incapacidad para afrontar emergencias humanitarias, flujos de refugiados, entre otros.

En algunos casos la debilidad estatal, la gradual decadencia institucional y la inestabilidad política derivan en el fracaso del Estado y la pérdida del control del territorio hacia las fronteras. Espacios sin gobierno que facilitan el establecimiento de redes terroristas y la inestabilidad regional, ambas son preocupaciones fundamentales de la política de seguridad exterior estadounidense. Una región inestable puede originarse en virtud de la difusión de Estados fallidos. Allí el terrorismo, la proliferación nuclear, la propagación de enfermedades infecciosas, la degradación del medio ambiente y la inseguridad energética amenazan con desbordar las fronteras. Según Liana Sun Wyler «los documentos de seguridad nacional de EE.UU. generalmente tratan los Estados débiles en relación a cuatro áreas clave de amenaza: (1) el terrorismo, (2) la delincuencia internacional, (3) la proliferación nuclear y (4) la inestabilidad regional ${ }^{23}$.

El Informe de Revisión Cuatrienal de 2001 destaca los crecientes desafíos y amenazas que emanan de los territorios con debilidad y fracaso estatal. Según este documento, «la ausencia de gobiernos capaces o responsables de muchos países en amplias zonas de Asia, África y el hemisferio occidental crea un terreno fértil para que los actores no estatales se dediquen al tráfico de drogas, el terrorismo y otras actividades que se propagan a través de las fronteras.» ${ }^{24} \mathrm{El}$ mismo informe en $2006^{25}$ señala que una gobernanza más efectiva disminuye la posibilidad de Estados fallidos o espacios sin gobierno en los que terroristas puedan operar más fácilmente o tomar refugio.

La Estrategia de Seguridad Nacional estadounidense señala con términos análogos su enfoque frente al problema. En 2002 afirma que «América está ahora menos amenazado por Estados

${ }^{23}$ Liana Sun Wyler, Weak and Failing States: Evolving Security Threats and U.S. Policy, 2008. http://www.fas.org/ $\mathrm{sgp} / \mathrm{crs} / \mathrm{row} / \mathrm{RL} 34253 . \mathrm{pdf}$

${ }^{24}$ United States Department of Defense, Quadrennial Defense Review Report, 2001. http://www.defense.gov/ pubs/pdfs/qdr2001.pdf

25 United States Department of Defense, Quadrennial Defense Review Report, 2006. http://www.defense.gov/ qdr/report/Report20060203.pdf

26 Global Security. The National Security Strategy of the United States of America, 2002. http:// www.globalsecurity.org/military/library/policy/national/nss-020920.pdf 
conquistadores que por Estados en descomposición» ${ }^{26}$. Y en 2006 se indica que «los conflictos regionales pueden surgir de una amplia variedad de causas, incluido el mal gobierno, la agresión externa, las demandas de la competencia, la rebelión interna, rivalidades tribales y odios étnicos o religiosos. Si se dejan sin tratar, sin embargo, estas diferentes causas conducen a los mismos finales: los Estados fallidos, los desastres humanitarios y las áreas sin gobierno que pueden llegar a ser refugios seguros para los terroristas $\rangle^{27}$.

La Estrategia Nacional de Defensa 2005 destaca que «la ausencia de un gobierno eficaz en muchas partes del mundo crea santuarios para terroristas, delincuentes e insurgentes. Muchos Estados no pueden, y en algunos casos no quieren, ejercer un control efectivo sobre su territorio o fronteras, dejando espacios abiertos a la explotación hostil» ${ }^{28}$. Tres años más adelante expresa que «los conflictos locales y regionales, en particular, siguen siendo un problema grave e inmediato. Ellos con frecuencia exacerban los problemas transnacionales como el tráfico de personas, de drogas, el terrorismo y el tráfico ilícito de armas. Estados canallas y grupos extremistas a menudo tratan de aprovechar la inestabilidad causada por los conflictos regionales y el colapso del Estado o la aparición de zonas sin gobierno, pudiendo crear refugios para estos grupos ${ }^{29}$.

En general los documentos coinciden en señalar que el debilitamiento de los gobiernos y la pérdida del control territorial o una presencia marginal del Estado propician la porosidad de las fronteras y el surgimiento de espacios sin gobierno o refugios para terroristas y organizaciones criminales. En este sentido se generan todo tipo de problemas de seguridad, tanto conflictos civiles y crisis humanitarias como propagación del crimen organizado internacional, lo cual redunda en inestabilidad regional. Aunque se ha visto que la eclosión y diseminación del terrorismo no necesariamente está relacionada con los Estados fallidos, el debilitamiento de los gobiernos sí colige claros problemas fronterizos.

Según Ángel Rabasa las áreas sin gobierno se definen como «territorios en los cuales el Estado enfrenta desafíos significativos para establecer el control. Los territorios sin gobierno pueden ser Estados fallidos o en falla, tierras o fronteras marítimas pobremente controladas o áreas dentro de Estados inviables donde la autoridad del gobierno central no existe. Los territorios sin gobierno pueden también extenderse al espacio aéreo, por ejemplo, rutas aéreas a través de Sur y Centroamérica y el Caribe donde los países son incapaces de establecer control - y los

${ }^{27}$ The White House, The National Security Strategy of the United States of America, 2006. http://GeorgewbushWhitehouse.Archives.Gov/Nsc/Nss/2006/Nss2006.Pdf

${ }_{28}$ United States Department of Defense, The National Defense Strategy of the United States of America, 2005. http://www.defense.gov/news/Apr2005/d20050408strategy.pdf

${ }^{29}$ United States Department of Defense, National Defense Strategy, 2008.m http://www.defense.gov/news/ 2008\%20National\%20Defense\%20Strategy.pdf 
traficantes las usan para transportar drogas ilegales» ${ }^{30}$. En su informe señala los siguientes casos de estudio: la península arábiga, el Arco Sulawesi-Mindanao, el Corredor del Este de África, África del Oeste, el Cáucaso Norte, la frontera Colombia-Venezuela y la frontera Guatemala-Chiapas.

Para Robert D. Lamb un área sin gobierno es «un lugar donde el Estado o el gobierno central no puede o no tiene voluntad de extender el control, gobernar eficazmente o influir en la población local, donde un gobierno provincial, local, tribal o autónomo tampoco es capaz de gobernar eficazmente ${ }^{31}$. En este sentido, las áreas sin gobierno se consideran posibles refugios criminales, es decir, «un lugar o situación que permite a los actores ilegales operar mientras evaden la detección o captura, zonas sin gobierno, sub-gobernadas o mal gobernadas, así como áreas físicas impugnadas (...) o áreas no físicas explotables (virtuales) donde los actores ilegales pueden organizar, planear, recaudar fondos, comunicarse, reclutar, entrenar y operar con relativa seguridad $\rangle^{32}$.

Hasta ahora se ha establecido la relación existente entre los Estados fallidos y las áreas sin gobierno. En común la mayoría proliferan en virtud de varias lagunas en la gobernanza, y de la debilidad de las instituciones estatales, donde el gobierno no puede o no lleva a cabo efectivamente todas o algunas de sus funciones: seguridad, judicial, legal, económica, administrativa o de prestación de servicios públicos. Sumado a lo anterior, una segunda consideración de los factores que hacen posible las áreas sin gobierno permite identificar que las zonas fronterizas y ciertas características geográficas brindan condiciones que favorecen su disposición. Las zonas fronterizas ciertamente suelen ser regiones remotas, con baja densidad de población y a menudo con características geográficas desérticas, costeras o con vegetación densa que dificultan una cobertura adecuada y un mínimo de presencia estatal.

No obstante, el supuesto según el cual los terroristas pueden beneficiarse de la laxitud de la ley existente en estos Estados fallidos para participar en actividades económicas ilícitas, y financiar sus operaciones, amerita una mirada más atenta. Según Stewart Patrick, «la escasa capacidad de por sí no puede explicar por qué la actividad terrorista se concentra en regiones particulares, especialmente en Oriente Medio y el más amplio mundo musulmán, más que en otros lugares como el África central. Otras variables y dinámicas políticas, religiosas, culturales y factores geográficos, claramente moldean su distribución global» $\rangle^{33}$.

${ }^{30}$ Angel Rabasa, et al, Ungoverned Territories Understanding and Reducing Terrorism Risks, 2007. http:// www.rand.org/pubs/monographs/2007/RAND MG561.pdf

31 Robert D. Lamb, Ungoverned Areas and Threats from Safe Havens, 2008. http://www.cissm.umd.edu/papers/ files/ugash report final.pdf

32 Ibid.

${ }^{33}$ Stewart M. Patrick, Weak States and Global Threats: Fact or Fiction?, 2006. http://www.twq.com/06spring/ docs/06spring_patrick.pdf 
Stewart Patrick sugiere una limitación a la relación entre terrorismo y el concepto de espacios sin gobierno. Para el autor «la aparición de un verdadero oasis requiere más que la ausencia de un Estado, el apoyo de los que detentan el poder local y la simpatía, o al menos la aquiescencia de la población local $\rangle^{34}$. Lo cual sugiere que alianzas más duraderas en los refugios seguros se cimentarían sobre la base de brechas en la legitimidad del gobierno, afinidades étnicas, lingüísticas, culturales o políticas y no exclusivamente de deficiencias en la capacidad de gobierno.

Por supuesto que la existencia de estas condiciones geográficas, políticas y civiles no conlleva en sí misma la formación de un área sin gobierno, por el contrario, es la acción de los actores ilegales lo que lo hace factible. Lo cierto es que grupos terroristas, movimientos insurgentes y la delincuencia organizada a menudo operan en diferentes formas y explotan estas condiciones y recursos locales ya sea para obtener ganancias económicas o para conseguir objetivos políticos. De entre estos tipos de actores es la delincuencia organizada transnacional la que abarca un amplio abanico de actividades ilegales en estas zonas. Según Liana Sun Wyler, «desde la Guerra Fría, la comunidad internacional ha visto un aumento en el número de grupos de delincuencia transnacional emergente en los paraísos de la debilidad y Estados propensos a los conflictos especialmente en los Balcanes, Asia Central y África Occidental» ${ }^{35}$.

A pesar de que no hay una única definición aceptada de delincuencia organizada transnacional, puesto que es una categoría amplia, la Organización de las Naciones Unidas ONU buscó una definición suficientemente amplia en la Convención contra la Delincuencia Organizada Transnacional que permitirá un mejor entendimiento. Según la ONU un grupo delictivo organizado «se entenderá como un grupo estructurado de tres o más personas, existente durante un período de tiempo y que actúe concertadamente con el propósito de cometer uno o más delitos graves o delitos tipificados de conformidad con la presente Convención, a fin de obtener, directa o indirectamente, beneficio financiero o de orden material» ${ }^{36}$.

Sin limitarse a formas específicas en que opera la delincuencia internacional, esta ajusta su asociación a diferentes Estados fallidos de acuerdo a su actividad. El tráfico ilícito de estupefacientes y el contrabando de armas habitualmente se beneficia del flujo a través de las fronteras mientras la falsificación y el fraude financiero aprovechan la infraestructura de los Estados fuertes.

\footnotetext{
34 Stewart M. Patrick, Are 'Ungoverned Spaces' a Threat?, 2010. http://www.cfr.org/publication/21165/ are ungoverned_spaces_a threat.html?breadcrumb $=\% 2$ Fbios $\% 2$ F $5863 \% 2$ Fstewart m patrick

35 Liana Sun Wyler, Weak and Failing States: Evolving Security Threats and U.S. Policy, 2008. http://www.fas.org/ sgp/crs/row/RL34253.pdf

${ }^{36}$ UNODC, United nations convention against transnational organized crime and the protocols thereto, 2004. http://www.unodc.org/documents/treaties/UNTOC/Publications/TOC\%20Convention/TOCebook-e.pdf
} 


\section{Cuadro 1. \\ Principales actividades a que se dedica la delincuencia organizada ${ }^{37}$.}

\begin{tabular}{|l|l|}
\hline \multicolumn{1}{|c|}{ Primary activities (subject of business) } & \multicolumn{1}{|c|}{ Enabling activities } \\
\hline Counterfeiting & Corruption of officials \\
\hline Drug production and trafficking & Violence, threats and intimidation \\
\hline Extortion and protection rackets & \\
\hline Illegal arms dealing & Money laundering \\
\hline Illegal vice: gambling and prostitution & \\
\hline $\begin{array}{ll}\text { Illegal provision of services (e.g.) unauthorized } \\
\text { waste disposal) }\end{array}$ & \\
\hline Labour racketeering & \\
\hline Loan sharking & \\
\hline Marine piracy & \\
\hline People trafficking & \\
\hline Smuggling (e.g. stolen vehicles, art, contraband) & \\
\hline Theft, robbery, hijacking, kidnapping, murder & \\
\hline Fraud, white-collar and corporate crime & \\
\hline
\end{tabular}

De acuerdo con la ONUDC las drogas ilícitas, la delincuencia organizada, la corrupción y el terrorismo son amenazas a nivel mundial que no respetan fronteras. El advenimiento de estos peligros trae consigo la difusión de «nuevos informes sobre la trata de mujeres jóvenes, el tráfico ilícito de migrantes, la corrupción de alto nivel, complots terroristas, la delincuencia organizada y el tráfico de drogas» ${ }^{38}$. Los vínculos entre estas amenazas (a excepción del terrorismo) descansan sobre un denominador común: la debilidad estatal y los Estados fallidos, como lo ilustra la Gráfica 4.

Según la UNODC el sudeste de Europa sigue siendo la principal región de tránsito de heroína destinada a Occidente. Las dinámicas de ilegalidad en la región están «relacionadas con el tráfico ilícito y otras actividades del crimen organizado como el blanqueo de dinero, la corrupción y la posibilidad de la financiación del terrorismo. El tratamiento de

37 Tomado de Quentin Reed, Squeezing a Balloon? Challenging the nexus between organised crime and corruption, 2009. http://www.cmi.no/publications/file/3399-squeezing-a-balloon.pdf

${ }^{38}$ UNODC, Towards security and justice for all: making the world safer from drugs, crime and terrorism, 2006. http://www.unodc.org/pdf/ctoccop_2006/V0657207e.pdf 


\section{Gráfica 4. Los vínculos entre las drogas, la delincuencia y el terrorismo ${ }^{39}$.}

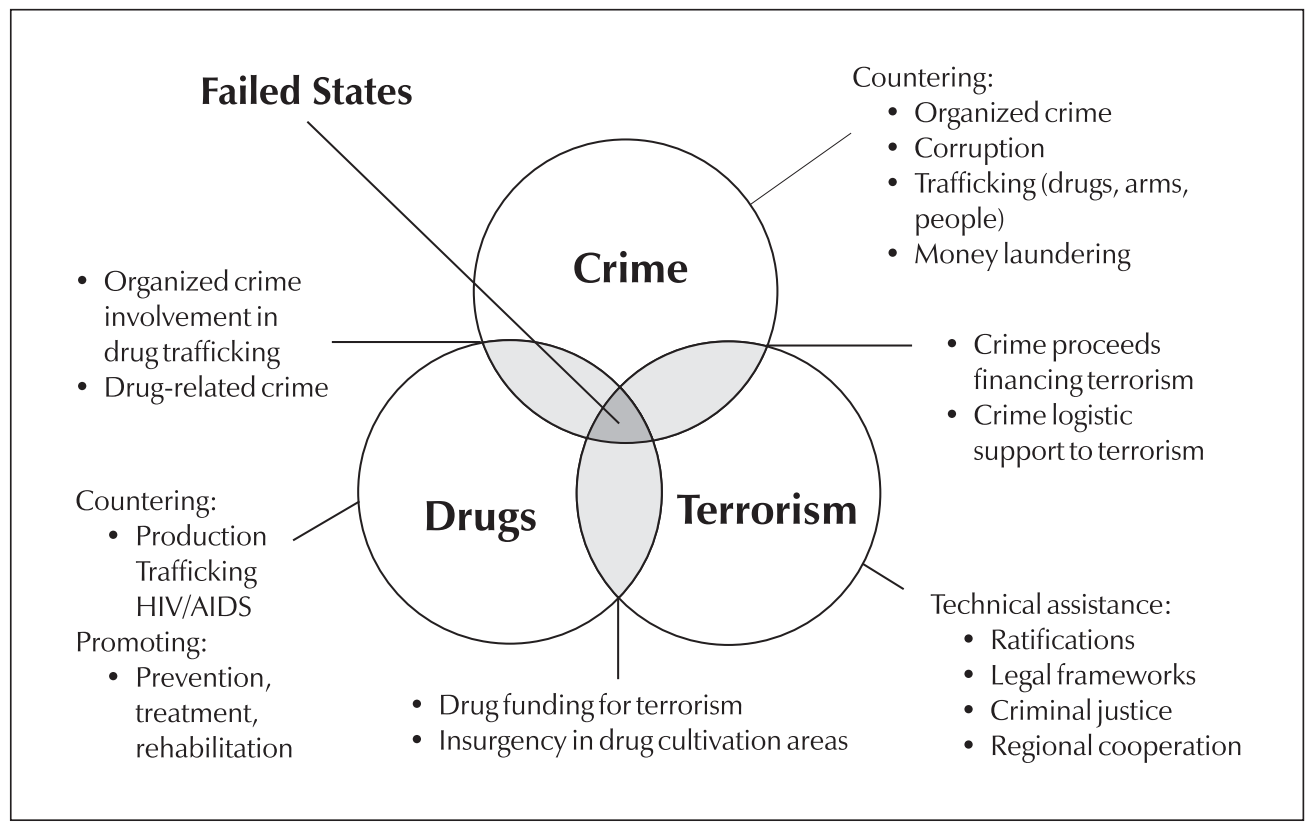

estas amenazas transnacionales requiere el fortalecimiento del gobierno y las instituciones dentro de la región $\gg^{40}$.

Para el caso de África Occidental, la UNODC presenta una evaluación de las amenazas que se ciernen en la región y la hacen vulnerable a la delincuencia organizada. Esta es una de las zonas más pobres de la tierra, y los conflictos violentos en muchos de estos países agravan una gobernabilidad débilmente constituida. Allí, a lo largo del territorio se extienden las rutas de tráfico ilícito donde «los criminales aprovechan estas condiciones para el tráfico de una gama de productos a través de la región: las drogas (principalmente cocaína de Suramérica a Europa), cigarrillos, armas y municiones; personas (destinadas a la inmigración ilegal o el comercio sexual); la falsificación de medicamentos, los residuos tóxicos (incluyendo e-waste); petróleo; y los recursos naturales (como madera y diamantes) $\rangle^{41}$.

39 Tomado de UNODC, Towards security and justice for all: making the world safer from drugs, crime and terrorism, 2006. http://www.unodc.org/pdf/ctoccop_2006/V0657207e.pdf

40 UNODC, Promoting the Rule of Law and Human Security in South Eastern Europe Regional Programme (2009-2011), 2009. http://www.unodc.org/documents/commissions/WG-GOVandFiN/Regional_Programme_endorsed.pdf

${ }_{41}$ UNODC, Transnational Trafficking and the Rule of Law in West Africa: A Threat Assessment, 2009. http:// www.unodc.org/documents/data-and-analysis/Studies/West_Africa_Report_2009.pdf 
Otra evaluación de la UNODC sugiere para la región de Asia Central que «la delincuencia organizada transnacional en Asia Central representa una grave amenaza para la región inhibiendo el surgimiento de sociedades estables $\rangle^{42}$. El informe identifica el tráfico de drogas, seres humanos y armas de fuego, el fraude y la corrupción como los principales delitos en el Asia central. Con Tayikistán, Turkmenistán y Uzbekistán, que comparten fronteras con Afganistán, el mayor productor de opio y sus derivados en el mundo, el Asia Central se configura como el mejor ejemplo de una amenaza fronteriza y regional. No sobra decir que estos países se ubican en el nivel crítico o en alerta del Failed State Index.

La región limítrofe entre Pakistán y Afganistán permite observar las implicaciones negativas de un área fronteriza sin gobierno, perteneciente a un Estado fallido. A propósito de Waziristán, en la frontera de Pakistán con Afganistán, es posible afirmar que «La presencia del Estado en los territorios fronterizos administrados por el gobierno federal siempre ha sido tenue» ${ }^{43}$. De tal forma se acentúa la presencia de redes criminales y el despliegue de rutas de narcotraficantes a lo largo de su territorio. Las repercusiones regionales de este comercio ilegal se aprecian en la Gráfica 5.

\section{Gráfica 5. Destinos de exportaciones de opio y heroína/morfina ${ }^{44}$}
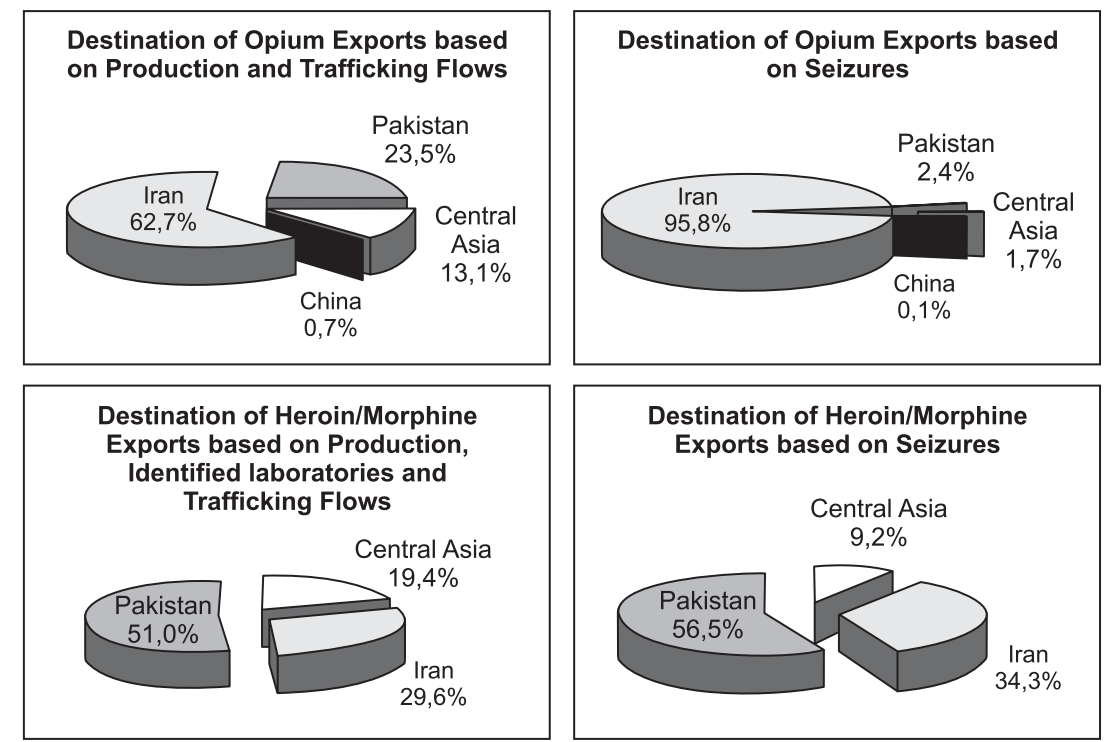

Source: UNODC, Afghanistan Opium Survey 2007, October 2007.

42 UNODC, An assessment of transnational organized crime in Central Asia, 2007. http://www.unodc.org/ documents/organized-crime/Central_Asia_Crime_Assessment.pdf

43 Angel Rabasa, et al, Ungoverned Territories Understanding and Reducing Terrorism Risks, 2007. http:// www.rand.org/pubs/monographs/2007/RAND_MG561.pdf

44 Tomado de UNODC, Illicit Drug Trends in Afghanistan, 2008. http://www.unodc.org/documents/regional/ central-asia/llicit\%20Drug\%20Trends\%20Report_Afg\%2013\%20June\%202008.pdf 
El tráfico de drogas en Afganistán sigue tres líneas generales: la «ruta septentrional» a través de Asia Central; la «ruta occidental» a través de Irán; y la «ruta sur», a través de Pakistán. El tráfico de drogas y precursores químicos se ve facilitado por la falta de eficacia del control gubernamental y por las características geográficas de las fronteras en algunas áreas en particular. Según lo sugiere el documento de la ONUDC «Algunas partes de la frontera no están bajo el control del gobierno, particularmente en las zonas a lo largo de la frontera sur con Pakistán (Hilmand, Nimroz y Kandahar). Los traficantes también se cree que utilizan las rutas principales de transporte para aprovechar las numerosas fronteras verdes. Según el gobierno afgano, hay al menos 167 rutas no oficiales para cruzar la frontera entre Afganistán y sus países vecinos» ${ }^{45}$.

\section{Mapa 1. Los mercados de opio, heroína, laboratorios de procesamiento y pasos no oficiales, en una zona de Estados fallidos. Pasos de Frontera ${ }^{46}$}

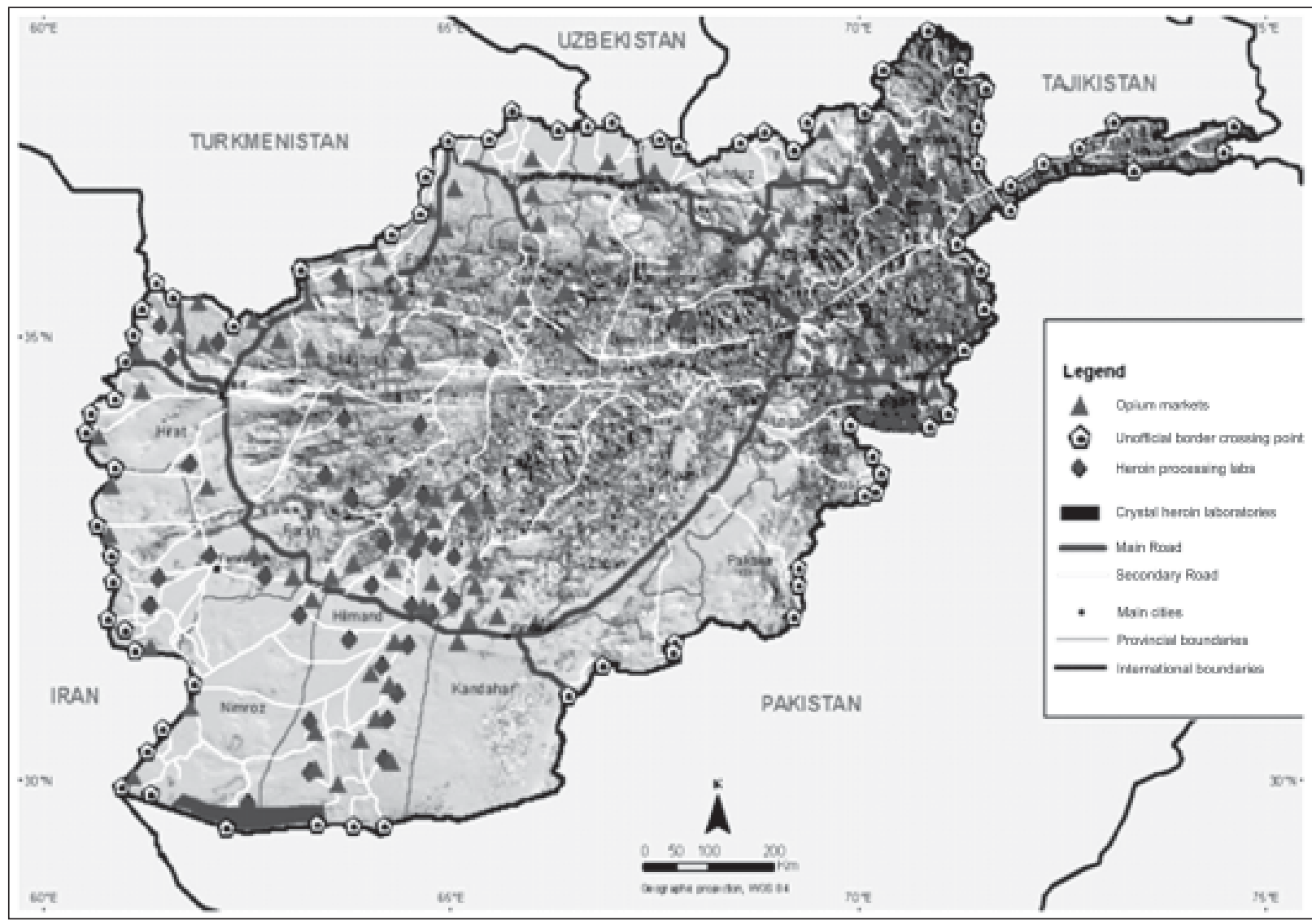

45 Ibid.

46 Tomado de UNODC, Illicit Drug Trends in Afghanistan, 2008. http://www.unodc.org/documents/regional/ central-asia/Illicit\%20Drug\%20Trends\%20Report_Afg\%2013\%20June\%202008.pdf 


\section{ESTADOS FALLIDOS Y REFUGIADOS}

Además de los problemas de tráficos ilegales entre las fronteras de los Estados fallidos y sus vecinos, está también la cuestión de los refugiados, lo cual plantea serios retos, tanto para los Estados receptores, como para las instituciones supraestatales que trabajan al respecto, como el ACNUR. Los refugiados son un tipo de migrantes que, a diferencia de aquellos que se movilizan de su lugar de vivienda hacia otro por motivos económicos, lo hacen por razones fundamentalmente políticas ${ }^{47}$.

Por migrante se entenderá, de acuerdo con el Programa de las Naciones Unidas para el DesarroIlo PNUD en su informe anual de Desarrollo Humano 2009, aquella persona que cambia su lugar habitual de residencia, ya sea en otro país o dentro del mismo. Así mismo, se denomina como emigrante a aquella persona que cambió su residencia a otro lugar, o en otras palabras, la persona que se va de su lugar original de vivienda, en tanto que el inmigrante es aquel sujeto que reside en un país o región de acogida que no es su lugar de origen ${ }^{48}$.

El Fondo de las Naciones Unidas encuentra dentro de las causas fundamentales de la migración la búsqueda de una vida mejor para el núcleo familiar; las marcadas diferencias en los ingresos recibidos por regiones; las políticas migratorias y laborales de los países de destino y origen; los conflictos de carácter social y político; el daño al medio ambiente, dentro de lo cual implica en algunos casos la pérdida de tierras de cultivo, bosques y pastizales; la migración de jóvenes con mayor nivel académico ${ }^{49}$.

Un tipo de migración corresponde al desplazamiento interno. El Comité Internacional de la Cruz Roja, otra de las instituciones que tiene entre sus programas el apoyo a los desplazados, cita a la Comisión de Derechos Humanos de las Naciones Unidas en su informe del 11 de febrero de 1998 y dice: «(...) se entiende por desplazados internos las personas o grupos de personas que se han visto forzadas u obligadas a escapar o huir de su hogar o de su lugar de residencia habitual, en particular como resultado, o para evitar los efectos, de un conflicto armado, de situaciones de violencia generalizada, de violaciones de los derechos humanos o de catástrofes naturales o provocadas por el ser humano, y que no han cruzado una frontera estatal internacionalmente reconocida $\rangle^{50}$.

El caso colombiano es el de mayor alarma respecto al desplazamiento interno, siendo de tres millones el número personas desplazadas, según datos del ACNUR para el mes de junio de

\footnotetext{
47 Jeremy Hein, Refugees, immigrants and the State, Annual Reviews, 1993, p. 54-55.

48 PNUD, Informe sobre Desarrollo Humano 2009, Grupo Mundi-Prensa, 2009, p. 224-225.

${ }^{49}$ Consejo Nacional de Población, Migración mundial, 2005. http://www.conapo.gob.mx/mig_int/s2008/pdfs/ 01.pdf.

${ }^{50}$ Comité Internacional de la Cruz Roja, Desplazados internos, CICR, 2008, p. 5.
} 
2009. Si bien el informe no ha modificado sus cifras en comparación con los datos del año 2007, en el cual se hablaba también de tres millones de desplazados en Colombia, tal situación no desconoce la gravedad del problema, siendo el 6.6\% de la población total del país. En la Tabla 4 se referencian los seis primeros países en desplazamiento interno, de los cuales cinco se encuentran en la lista de estados fallidos 2009 de Fund for Peace en la categoría de Estados en condición crítica (Irak, Congo, Somalia, Sudán y Uganda).

Tabla 4.

Desplazados internos años 2007 y 2009. Fuente: ACNUR.

\begin{tabular}{|l|r|r|}
\hline \multicolumn{1}{|c|}{ País } & $\mathbf{2 0 0 7}^{\mathbf{5 1}}$ & \multicolumn{1}{c|}{$\mathbf{2 0 0 9}^{\mathbf{5 2}}$} \\
\hline Colombia & 3.000 .000 & 3.000 .000 \\
\hline Irak & 1.834 .000 & 2.647 .000 \\
\hline Congo, Rep. Democrática & 1.075 .000 & 1.406 .000 \\
\hline Somalia & 400.000 & 1.277 .000 \\
\hline Sudán & 1.325 .000 & 1.201 .000 \\
\hline Uganda & 1.586 .000 & 853.000 \\
\hline
\end{tabular}

El cuadro anterior muestra que el problema en Colombia, si bien se ha estabilizado, no ha disminuido, mientras que en Sudan y Uganda los índices han mejorado, y en los casos de Irak, Congo y Somalia el aumento es notorio, viéndose en Irak y Somalia un aumento de cerca del $30 \%$ y $200 \%$ respectivamente.

Los refugiados son otro tipo de migrantes. La Convención de Ginebra define al refugiado como una «persona o grupo de personas que han debido huir de su país de origen por tener fundados temores de ser perseguidos por motivos de raza, religión, nacionalidad, opinión política o pertenencia a un determinado grupo social y que no pueden o no quieren regresar» ${ }^{\mathbf{5}}$. Junto con los desplazados internos, los refugiados se diferencian de los migrantes económicos en tanto su movilidad depende de factores políticos que los violentan y provocan su cambio de residencia, mientras los migrantes económicos buscan lugares donde desarrollar sus actividades económicas y aumentar sus ingresos.

51 ACNUR, Tendencias globales sobre refugiados 2006, ACNUR, 2007.

${ }^{52}$ ACNUR, 2008 global trends, ACNUR, 2009. http://www.unhcr.org/pages/49c3646c4d6.html

53 PNUD, Informe sobre Desarrollo Humano 2009, Grupo Mundi-Prensa, 2009, p. 226-227 o ACNUR http:/ /www.acnur.org/index.php?id_pag=29. 
La diferencia fundamental entre los refugiados y los desplazados internos es el cruce de fronteras internacionales. En algunos casos los refugiados acuden a la figura del asilo para arribar a un país extraño de manera legal, con garantías de respeto a sus derechos y facilidades laborales y de vivienda junto con su familia. El PNUD define el asilo como el otorgamiento por parte de un estado de protección en su territorio a una persona o grupo para escapar de persecución o amenaza grave ${ }^{54}$. Sin embargo, el número de asilados es inferior en comparación con aquellos refugiados que cruzan las fronteras inmediatas sin un lugar de llegada claro, lo que Jeremy Hein denomina como de primer asilo o de llegada inicial ${ }^{55}$.

Los 10 países que encabezan los índices de refugiados según el ACNUR para el mes de junio de 2009 son, en su orden, Afganistán, Irak, Somalia, Sudan, Colombia, Congo, Territorios Palestinos Ocupados, Vietnam, Burundi y Turquía. El cuadro número 2 muestra el número de refugiados procedentes de cada uno de estos Estados y el porcentaje que representan para la totalidad de la población de cada país.

Tabla 5.

Países de mayor emisión de refugiados junio 2009. Fuente: ACNUR ${ }^{56}$.

\begin{tabular}{|l|c|c|}
\hline \multicolumn{1}{|c|}{ País de origen } & $\begin{array}{c}\text { Número de } \\
\text { refugiados }\end{array}$ & $\begin{array}{c}\text { \% de su } \\
\text { población }\end{array}$ \\
\hline Afganistán & 2.833 .128 & 9.8 \\
\hline Irak & 1.903 .519 & 7.1 \\
\hline Somalia & 561.154 & 6.8 \\
\hline Sudan & 419.248 & 1.0 \\
\hline Colombia & 373.532 & 0.8 \\
\hline Congo, Rep. Dem. & 367.995 & 0.6 \\
\hline Territorios Palestinos Ocupados & 340.016 & 3.4 \\
\hline Vietnam & 328.183 & 0.3 \\
\hline Burundi & 281.592 & 4.5 \\
\hline Turquía & 214.378 & 0.2 \\
\hline
\end{tabular}

${ }^{54}$ PNUD, Informe sobre Desarrollo Humano 2009, Grupo Mundi-Prensa, 2009, p. 224.

55 A diferencia de los migrantes económicos, que en gran medida definen su país de destino con base en la recepción suya por parte de familiares o amigos residentes en el lugar de llegada, los refugiados parten, un gran número de ellos, a los países vecinos donde no conocen a nadie que les dé albergue inicial, o si lo conocen, lo común es que sea en los mismos países vecinos. En un número reducido pueden ir a países desarrollados y encontrar allí recepción por parte de algún allegado. Jeremy Hein, Refugees, immigrants and the State, Annual Reviews, 1993, p. 49-50 y 52.

${ }^{56}$ ACNUR, 2008 global trends, ACNUR, 2009. http://www.unhcr.org/pages/49c3646c4d6.html 
Fund for Peace ubica en una escala de 1.0 a 10.0 el grado de falla de cada Estado. El correspondiente al ítem de refugiados y desplazados se explica como el «desarraigo forzoso de grandes comunidades, como resultado de la violencia aleatoria y/o de la represión, causando escasez de alimentos, enfermedades, falta de agua potable, competencia por las tierras y la confusión, que puede derivar en grandes problemas humanitarios y de seguridad, dentro de sus países o más allá de sus fronteras» ${ }^{57}$. Así, Somalia (9.9), Sudán (9.8), República Democrática del Congo (9.6), Chad (9.4), Uganda (9.3), Sri Lanka (9.3), Siria (9.2), Colombia (9.2), Zimbabue (9.1) y Kenia (9.0) son los 10 primeros Estados en falla respecto al índice de refugiados de dicha publicación.

Es importante recordar que en esta lista se incluye el desplazamiento interno. Sin embargo, Fund for Peace ubica a Afganistán en el puesto 14 con una calificación de 8.9, a Israel/Cisjordania en el 22 con 8.0, a Vietnam en el puesto 78 con 5.3, a Burundi en la posición 21 con 8.1 y a Turquía en la ubicación 50 con 6.6.

Ahora bien, si se comparan las cifras de 2007 de ACNUR con las de los diez primeros países en índice de refugiados para el año 2009 de la misma institución, encontramos lo siguiente:

Tabla 6.

Refugiados junio / 2007 y junio / 2009.

\begin{tabular}{|l|c|c|}
\hline \multicolumn{1}{|c|}{ País de origen } & $\begin{array}{c}\text { No. refugiados } \\
\mathbf{2 0 0 7 ^ { 5 8 }}\end{array}$ & $\begin{array}{c}\text { No. refugiados } \\
\mathbf{2 0 0 9}\end{array}$ \\
\hline Afganistán & 2.107 .500 & 2.833 .128 \\
\hline Irak & 1.450 .900 & 1.903 .519 \\
\hline Somalia & 464.250 & 561.154 \\
\hline Sudán & 686.300 & 419.248 \\
\hline Colombia & 72.796 & 373.532 \\
\hline Congo, Rep. Dem. & 401.900 & 367.995 \\
\hline Territorios Palestinos Ocupados & 334.100 & 340.016 \\
\hline Vietnam & 374.270 & 328.183 \\
\hline Burundi & 396.500 & 281.592 \\
\hline Turquía & 227.233 & 214.378 \\
\hline
\end{tabular}

57 The Fund For Peace. Failed States Index 2009. http://www.fundforpeace.org/web/index.php?option= com_content\&task $=$ view\&id $=99 \&$ Itemid $=140$.

58 ACNUR, Tendencias globales sobre refugiados 2006, ACNUR, 2007. ACNUR, 2008 global trends, ACNUR, 2009. http://www.unhcr.org/pages/49c3646c4d6.html.

59 ACNUR, 2008 global trends, ACNUR, 2009. http://www.unhcr.org/pages/49c3646c4d6.html. 
Si bien algunos de estos países han aumentado su número de personas refugiadas, como en el caso de los tres primeros Estados referidos, al igual que el caso colombiano y el de los territorios palestinos, los demás han mostrado una reducción en sus indicadores. Aun así, seis de estos Estados (Afganistán, Irak, Somalia, Sudán, Rep. Dem. del Congo y Burundi) se ubican en la categoría de Críticos en la lista de Fund for Peace, mientras los restantes cuatro se encuentran, según la misma publicación, en Alerta. Es decir que el índice de refugiados concuerda en gran medida con el indicador de falla estatal.

Por otra parte, al revisar los países que son receptores de refugiados se encuentra lo siguiente:

Tabla 7.

Primeros 10 países receptores de refugiados. ACNUR $2009^{60}$.

\begin{tabular}{|l|c|}
\hline País receptor & Refugiados recibidos \\
\hline Pakistán & 1.780 .935 \\
\hline Siria & 1.105 .698 \\
\hline Irán & 980.109 \\
\hline Alemania & 582.735 \\
\hline Jordania & 500.413 \\
\hline Chad & 330.510 \\
\hline Tanzania & 321.909 \\
\hline Kenia & 320.605 \\
\hline China & 300.967 \\
\hline Reino Unido & 292.097 \\
\hline
\end{tabular}

Lo que está claro inicialmente es que existe una relación entre los índices de Estados de origen y los receptores de refugiados y, aún más, de estos con los índices de Estados fallidos, lo que confirma la idea de que el problema de desplazamiento de refugiados resulta de impacto en términos regionales, en tanto son los países vecinos de los Estados fallidos los que ven desestabilizada su situación política interna.

Si se revisa, por ejemplo, Pakistán e Irán limitan con Afganistán; Siria, Jordania e Irán son países vecinos de Irak; Chad colinda con la República Democrática del Congo, Sudán, Kenia y la

${ }^{60}$ Ibid.

ESTADOS FALLIDOS: iAMENAZA GLOBAL O REGIONAL? 
República Centroafricana -estos dos últimos con altos índices de refugiados e igualmente parte de los Estados fallidos del Fund for Peace-; Kenia, que limita con Somalia; Tanzania, limitando con la misma Kenia y con la República Democrática del Congo; y China, que limita con Vietnam y Birmania, este último otro Estado fallido con alto indicador de refugiados.

Si miramos la lista aparecen Alemania y Reino Unido, e incluso en la undécima posición se ubica Estados Unidos, Estados que se encuentran en una condición de estabilidad y principales objetivos de solicitud de asilo por parte de los refugiados. Esto ratifica lo dicho inicialmente respecto al número de asilados en comparación con aquellos refugiados que traspasan las fronteras de su Estado y se establecen allí sin el reconocimiento legal de su condición. El número de refugiados recibidos en Alemania, Reino Unido y Estados Unidos es de 1.154.380, mientras que los ocho países restantes de mayor recepción de refugiados suman 5.641.146 personas, cifra muy superior ${ }^{61}$. No se puede decir que todos los refugiados de estos ocho países en las categorías de Críticos o de Alerta se encuentran allí ilegalmente, pero sí en su mayoría, así como tampoco se podría afirmar que todos aquellos refugiados de Alemania, Reino Unido y Estados Unidos se encuentran en condiciones de legalidad.

Los anteriores datos llevan a cuestionarse en qué medida el índice de refugiados de los Estados fallidos implican una amenaza regional. Hein indica, para el año de 1991, que los refugiados en gran parte conservaban la dinámica de movimiento periferia-periferia, de tercer mundo a tercer mundo $^{62}$, tendencia que se mantiene, en la medida en que el refugiado, en su huida, recurre al territorio de salvaguarda que encuentra más cercano, es decir, los países vecinos o en otros términos, dentro de la misma región.

Además los datos numéricos y la ubicación geográfica plantean la correlación entre los casos más significativos de emisión y recepción de refugiados y su condición de fallido. Así, en los casos destacados se podría afirmar, siguiendo a Hein, que existe una dinámica de movimiento entre estados Fallido-Fallido o en el mejor de los casos, Fallido-En Alerta. De hecho, ya para 1991 Somalia, Burundi, Afganistán, Palestina, entre otros que hoy se consideran fallidos o en vías de fracaso, tenían altos índices de refugiados, e Irán, Sudán, Pakistán entre otros, recibían a los refugiados de sus países más próximos, Estados estos también fracasados o en vías de serlo ${ }^{63}$.

61 Ibid.

${ }^{62}$ Jeremy Hein, Refugees, immigrants and the State, Annual Reviews, 1993, p. 45.

63 Ibid., p. 45-46. 

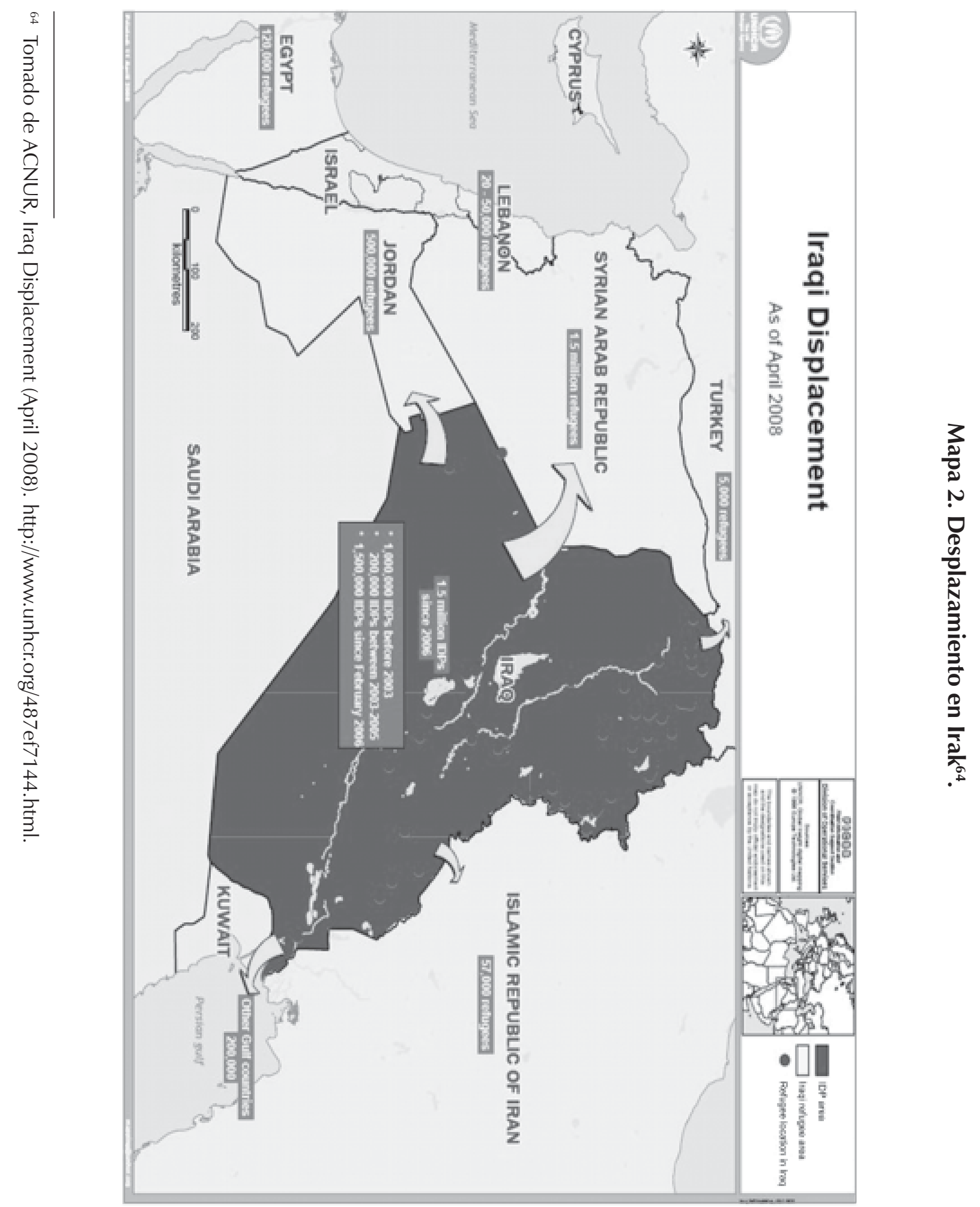


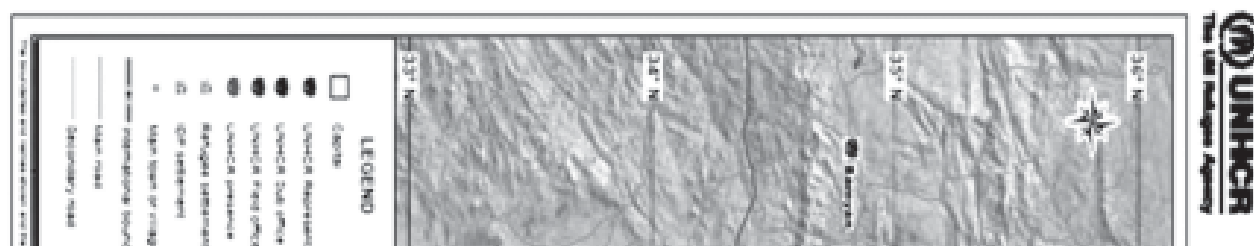



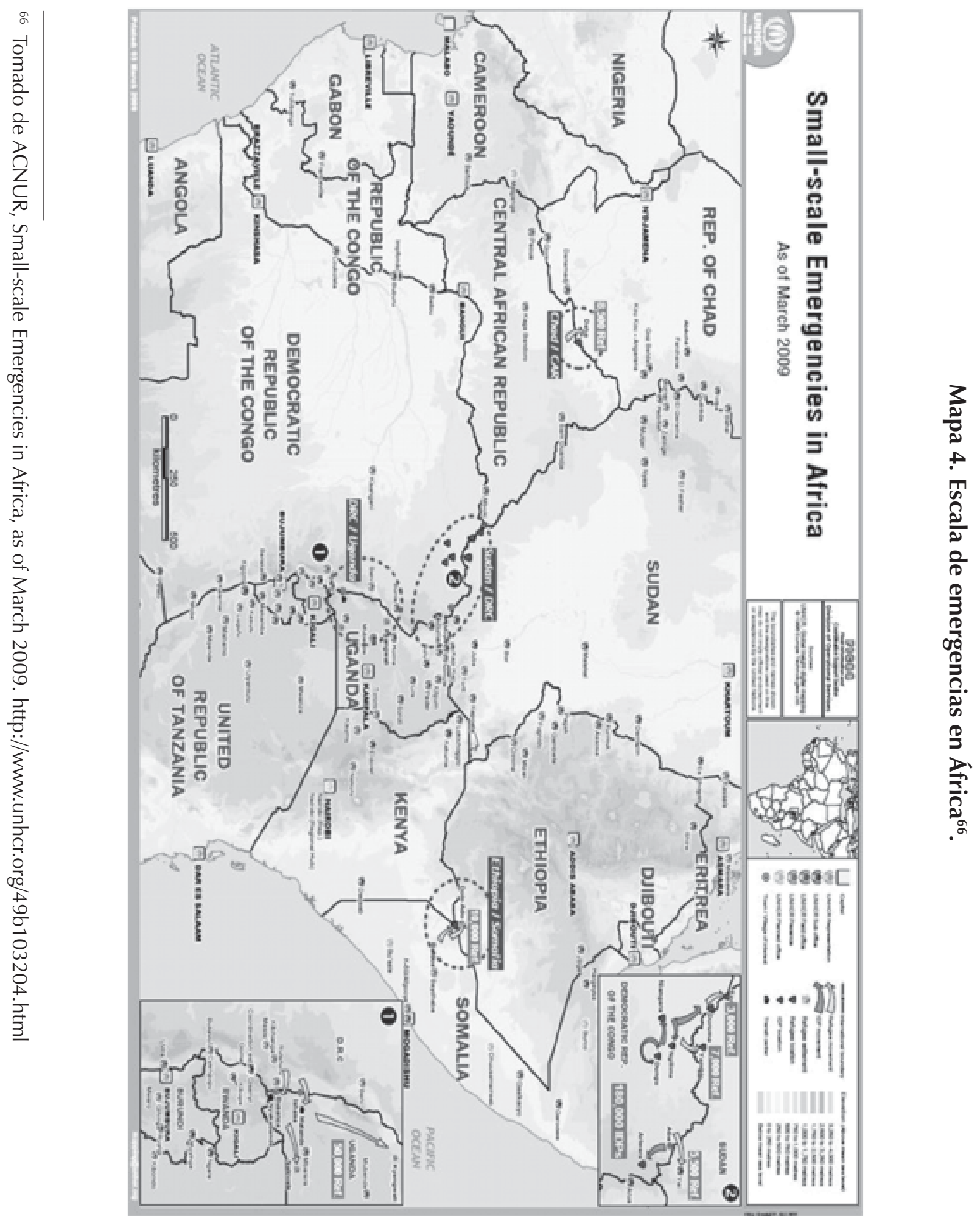
Los mapas 2 y 3 dan luces acerca del impacto del movimiento de refugiados de los dos Estados con mayores índices de refugiados, Afganistán e Irak, en los países vecinos, o mejor, su impacto regional en la dinámica de movimiento de personas refugiadas, máxime al mirar que son Pakistán y Siria los Estados que encabezan la lista de países receptores de refugiados y que, a su vez, son parte de la lista del Fund for Peace. Así mismo, el mapa 4 muestra los movimientos y los asentamientos de refugiados en la región centroafricana, donde encontramos a países que hacen parte de las listas tanto de emisión como de recepción de refugiados. Es notoria la ubicación en las regiones fronterizas del mayor número de campamentos de refugiados, debido a la proximidad y prontitud para la ubicación por parte de los refugiados.

Las cifras brindadas por el US Committee for Refugees and Immigrants en su publicación World Refugee Survey 2009, indican que Pakistán recibió para fines de 20081.775 .600 refugiados, de los cuales 1.774.400 procedían de Afganistán, y 1.200 de otros Estados; Siria recibió 1.763.900 refugiados, 1.200.000 de ellos iraquíes, 557.900 palestinos, 3.400 somalíes y un restante de 2.600 de otros países; Irán por su parte fue receptor de 993.600, 935.500 afganos y 58.100 iraquíes ${ }^{67}$.

Los problemas que de allí se desprenden son, en primer lugar, el gasto para el Estado receptor de recursos económicos y el desvío de los mismos que inicialmente eran para sus habitantes, ahora para los refugiados de países ajenos. Al respecto puede suceder que los Estados más desarrollados, como Estados Unidos, estén en capacidad de destinar recursos para los refugiados. De hecho el Estado norteamericano, por ejemplo, destinaba para 1991 el dinero suficiente para apoyar a los refugiados durante los cinco primeros años de estadía en su territorio. Sin embargo, en países con problemas económicos y políticos como Pakistán (número 10 en el índice de Estados fallidos), que recibe grandes flujos de refugiados, en su mayoría afganos -Afganistán se encuentra en el puesto 7-, lo normal es que el Estado no esté en las condiciones para garantizar su estadía, partiendo del hecho que ni siquiera a sus propios habitantes puede brindar todos los bienes políticos exigidos al aparato estatal.

La falta de políticas para refugiados en los Estados fallidos, tanto para evitar su desplazamiento como para la adecuada recepción, según sea el caso, lleva a que las Naciones Unidas, junto con otras instituciones internacionales, asuman y traten el problema que correspondería al Estado pero que no está en capacidad de asumir, creando el Sistema Internacional de Refugiados ${ }^{68}$. Vicenç Fisas afirma que los conflictos internos, que revisten el mayor número de enfrentamientos en el mundo, muy por encima de conflictos interestatales, producen una masa ingente de refugiados difíciles de gestionar por su magnitud y deben ser apropiados los procedimientos de ayuda por instituciones humanitarias internacionales ${ }^{69}$.

${ }^{67}$ US Committee for Refugees and Immigrants (USCRI). World Refugee Survey 2009. http://www.refugees.org/ FTP/WRS09PDFS/RefuandAsylumseek.pdf.

${ }_{68}$ Jeremy Hein, Refugees, immigrants and the State, Annual Reviews, 1993, p. 47.

${ }^{69}$ Vicenç Fisas, Cultura de paz y gestión de conflictos, Icaria Editorial S.A., 1998, p. 60. 
El desplazamiento de refugiados y la falta de apoyo por parte del Estado receptor puede generar dos consecuencias: la primera es el aumento de las condiciones de miseria entre la población refugiada y su consiguiente recurso de la ilegalidad para conseguir el sustento; la segunda es que junto con los refugiados también se trasladen al Estado receptor las dinámicas violentas que provocaron el éxodo, sumándole problemas de seguridad al país vecino y a la región en general, como sucedió en el año de 1999 en Kosovo, región que para entonces era emisor de refugiados en grandes cantidades a países como Albania y Macedonia, y en condición de asilados a Alemania y Suiza ${ }^{70}$.

\section{CONCLUSIONES}

Aunque se haya afirmado continuamente que los Estados fallidos son tierra fértil para el crecimiento y diseminación de grupos terroristas, una inspección detallada de la ubicación de los países en el Failed State Index y los grupos terroristas por país, no permite vislumbrar un nexo. Al comparar los grupos terroristas en términos generales, es decir, teniendo como indicador su existencia, se encontró que existe un comportamiento similar entre los 38 países en estado crítico y los 38 países más exitosos. Los promedios y las medianas son muy cercanas, incluso un poco mayores en los Estados exitosos, por lo cual se puede pensar que existe mayor presencia terrorista en Estados fuertes que en Estados fallidos. Tampoco se ha podido observar una tendencia de acuerdo con las gráficas que sugiera descenso de la presencia terrorista a medida que los países se alejan de las posiciones de fracaso a las de éxito. El análisis de los países del G8 ofrece pistas sobre la ubicación de los grupos terroristas con respecto al país donde se sitúan: los datos muestran que el promedio en estos países duplica los demás.

Ahora bien, si el principal argumento que soportaba la visión de los Estados fallidos como amenaza global era aquel que los vinculaba con el terrorismo, y se ha visto que en buena medida carece de fundamento empírico, ¿en qué sentido pueden llegar a ser una amenaza los Estados fallidos, y que carácter tendría tal amenaza?

Los Estados fallidos son un factor de desestabilización regional, en tanto la recepción de los tráficos ilegales y las acciones de la delincuencia organizada trasnacional se cataliza generalmente tanto en el Estado fallido como en los Estados circundantes. El caso específico de la región fronteriza entre Afganistan-Pakistan ilustra ciertamente las amenazas que se filtran en fronteras

70 En los campos de refugiados se cobijan contendientes violadores de derechos humanos que continúan controlando a la población ahora refugiada. Las organizaciones humanitarias siguen alimentando a la población, entre la cual se incluyen los genocidas y asesinos que planean continuar con los combates. Las organizaciones humanitarias se encuentran en la situación de elegir entre continuar dando soporte a las facciones beligerantes o retirar el apoyo a los refugiados, es decir, dejarlos sin garantías sanitarias y alimentarias. Vicenç Fisas, Cultura de paz y gestión de conflictos, Icaria Editorial S.A., 1998, p. 100, 103. 
porosas, causadas por el debilitamiento estatal y la carencia de capacidad de una gobernanza eficaz. Al igual que el ejemplo particular anterior, el análisis de regiones como el sudeste de Europa, el África Occidental y el Asia Central permiten corroborar la tesis de la amenaza regional de los Estados fallidos.

Los Estados fallidos también desestabilizan sus regiones por la emisión de refugiados a los países vecinos, receptores de masas ingentes de migrantes que huyen de las dinámicas violentas acaecidas al interior de su país de origen, y que conllevan a la complicación de las políticas de seguridad y economía de los países de alojo, los cuales son, en su mayoría, Estados que igualmente presentan dinámicas internas que los ubican en la misma categoría de Fallidos o en alerta. Existe una correspondencia lógica entre los principales países emisores de refugiados y aquellos que son receptores de los mismos. El caso de Afganistan-Pakistan e Irán, y el de Irak-Siria e Irán, por mirar sólo algunos, confirman la tesis de la relación Fallido-Fallido respecto a los desplazamientos de los refugiados. Es decir, los refugiados acuden a países vecinos que por lo general se hallan también en situación de debilidad estatal.

\section{BIBLIOGRAFÍA}

- $\quad$ ACNUR, 2008 global trends, ACNUR. 2009.

- _Iraq Displacement (April 2008). http://www.unhcr.org/487ef7144.html

- - Pakistan, Refugee camps in the North-West Frontier Province - January 2008. http://www.unhcr.org/ $\underline{\text { 3cc91a0b2.html }}$

- - Small-scale Emergencies in Africa, as of March 2009. http://www.unhcr.org/49b103204.html

- - Tendencias globales sobre refugiados 2006, ACNUR. 2007.

- Aidan Hehir, The Myth of the Failed State and the War on Terror: A Challenge to the Conventional Wisdom, Journal of Intervention and Statebuilding, 2007.

- Anna Simons y David Tucker, The Misleading Problem of Failed States: a 'socio-geography' of terrorism in the post-9/11 era, Third World Quarterly, Vol. 28, No. 2, 2007.

- Angel Rabasa, et al, Ungoverned Territories Understanding and Reducing Terrorism Risks, 2007. http:// www.rand.org/pubs/monographs/2007/RAND_MG561.pdf

- Brennan M. Kraxberger, Failed states: temporary obstacles to democratic Diffusion or fundamental holes in the world political map?, Third World Quarterly, 2007.

- Comité Internacional de la Cruz Roja, Desplazados internos, CICR. 2008. 
- Consejo Nacional de Población, Migración mundial. 2005. http://www.conapo.gob.mx/mig_int/s2008/ pdfs/01.pdf

- CWS, Comission on Weak States and US National Security. On the Brink: Weak States and US National Security, 2004. http://www.cgdev.org/doc/books/weakstates/Full_Report.pdf

- Dan Bulley, 'Foreign' Terror? London Bomings, Resistance and the 'Failing State', International Studies Association 48th Annual Convention, Hilton Chicago, 2007.

- D. C. Jordan, Drug Politics: Dirty Money and Democracies. Norman: University of Oklahoma Press, 1999.

- $\quad$ Edward Newman, Weak States, State Failure, and Terrorism, Terrorism and Political Violence, 2007.

- Estrategia Europea de Seguridad, Una Europa Segura en un Mundo Mejor, 2003. http://www.consilium.europa.eu/uedocs/cmsUpload/031208ESSIIES.pdf

- Foreign Policy, Indice de Estados fallidos 2009. http://www.fp-es.org/estados fallidos/index.html.

- H. R. Friman, y P. Andreas, eds., The Illicit Global Economy and State Power, Lanham, MD: Rowman \& Littlefield, 1999.

- Jeremy Hein, Refugees, immigrants and the State, Annual Reviews, 1993.

- Liana Sun Wyler, Weak and Failing States: Evolving Security Threats and U.S. Policy, 2008. http://www.fas.org/ sgp/crs/row/RL34253.pdf

- Luis Alberto Moreno, et al. A Failed Index?, Foreign Policy, No. 150, septiembre/octubre 2005.

- Morten Boas \& Kathleen Jenings, 'Failed States' and 'State Failure': Threats or Opportunities?, Globalizations Vol. 4, No. 4, 2007.

- National Memorial Instfor the Prevention of Terrorism. (MIPT). http://www.start.umd.edu/start/data/tops/

- NIC, National Intelligence Council, Mapping the Global Future,2004. http://www.foia.cia.gov/2020/ 2020.pdf

- $\quad$ NSS, National Security Strategy of the United States of America, 2006. http://www.strategicstudiesinstitute.army.mil/pdffiles/nss.pdf

- Patricia Moncada Roa, Los estados fallidos o fracasados: un debate inconcluso y sospechoso, Siglo del hombre editores, 2007.

- Peter Tikuisis, On the relationship between weak states and terrorism, Behavioral Sciences of Terrorism and Political Aggression, 2009.

- Pinar Bilgin y Adam Morton D., Historicising representations of 'failed states': beyond the cold-war annexation of the social sciences?. Third World Quarterly, Vol 23, No 1, 2002. 
- PNUD, Informe sobre Desarrollo Humano 2009, Grupo Mundi-Prensa, 2009.

- Quentin Reed, Squeezing a Balloon? Challenging the nexus between organised crime and corruption, 2009. http://www.cmi.no/publications/file/3399-squeezing-a-balloon.pdf

- Robert Dorff, Failed States After 9/11: What Did We Know and What Have We Learned?, International Studies Perspectives, 2005.

- Robert I. Rotberg, Failed States in a World of Terror, Foreign Affairs, julio/agosto 2002.

- - The New Nature of Nation-State Failure. The Washington Quarterly Volumen 25, número 3, 2002.

- Stewart Patrick, Are 'Ungoverned Spaces' a Threat? 2010. http://www.cfr.org/publication/21165/ are_ungoverned_spaces_a threat.html?breadcrumb $=\% 2$ Fbios $\% 2$ F $5863 \% 2$ Fstewart m patrick

- - Weak States and Global Threats: Fact or Fiction? 2006. http://www.twq.com/06spring/docs/ 06spring_patrick.pdf

- The 9/11 Comission Report, Final Report of the National Comission on Terrorist Attacks Upon the United States, 2003. http://www.strategicstudiesinstitute.army.mil/pdffiles/nss.pdf

- The Fund For Peace. Failed States Index 2009. http://www.fundforpeace.org/web/index.php?option=com content\&task=view\&id=99\&Itemid $=140$.

- The National Security Strategy of the United Kingdom, Security in an Interdependent World, 2008. http:/ /interactive.cabinetoffice.gov.uk/documents/security/national_security_strategy.pdf

- The White House, The National Security Strategy of the United States of America, 2006. http://GeorgewbushWhitehouse.Archives.Gov/Nsc/Nss/2006/Nss2006.Pdf

- United States Deparment of Defence, Quadrennial Defense Review Report, 2001.http://www.defense.gov/ pubs/pdfs/qdr2001.pdf

- United States Deparment of Defence, Quadrennial Defense Review Report, 2006. http://www.defense.gov/ qdr/report/Report20060203.pdf

- United States Deparment of Defence, The National Defence Strategy of the United States of America, 2005. http://www.defense.gov/news/Apr2005/d20050408strategy.pdf

- United States Deparment of Defence, National Defence Strategy, 2008. http://www.defense.gov/news/ 2008\%20National\%20Defense\%20Strategy.pdf

- UNODC, United nations convention against transnational organized crime and the protocols thereto, 2004. http://www.unodc.org/documents/treaties/UNTOC/Publications/TOC\%20Convention/TOCebooke.pdf

- UNODC, Towards security and justice for all: making the world safer from drugs, crime and terrorism, 2006. http://www.unodc.org/pdf/ctoccop_2006/V0657207e.pdf 
- UNODC, Promoting the Rule of Law and Human Security in South Eastern Europe Regional Programme (2009-2011), 2009. http://www.unodc.org/documents/commissions/WG-GOVandFiN/Regional Programme_endorsed.pdf

- UNODC, Transnational Trafficking and the Rule of Law in West Africa: A Threat Assessment, 2009. http:// www.unodc.org/documents/data-and-analysis/Studies/West_Africa_Report_2009.pdf

- UNODC, An assessment of transnational organized crime in Central Asia, 2007. http://www.unodc.org/ documents/organized-crime/Central_Asia_Crime_Assessment.pdf

- UNODC, Illicit Drug Trends in Afghanistan, 2008. http://www.unodc.org/documents/regional/centralasia/ Illicit\%20Drug\%20Trends\%20Report_Afg\%2013\%20June\%202008.pdf

- $\quad$ US Committee for Refugees and Immigrants (USCRI), World Refugee Survey 2009. http://www.refugees.org/ FTP/WRS09PDFS/RefuandAsylumseek.pdf

- U.S. Department of State, Country Reports on Terrorism 2008, 2009. http://www.state.gov/documents/ organization/122599.pdf

- Vicenç Fisas, Cultura de paz y gestión de conflictos, Icaria Editorial S. A., 1998.

- W. Reno, Warlord Politics and African States. Boulder, 1998. 